\title{
Decision of Adjuvant Systemic Treatment in HR+ HER2- Early Invasive Breast Cancer: Which Biomarkers Could Help?
}

This article was published in the following Dove Press journal: Cancer Management and Research

\author{
Marie Alexandre' \\ Aurélie Maran-Gonzalez ${ }^{2}$ \\ Marie Viala' \\ Nelly Firmin' \\ Véronique D'Hondt ${ }^{1,3,4}$ \\ Marian Gutowski ${ }^{5}$ \\ Céline Bourgier ${ }^{3,6}$ \\ William Jacot $\mathbb{D}^{1,3,4}$ \\ Séverine Guiu ${ }^{1,3,4}$ \\ 'Department of Medical Oncology, \\ Institut Régional du Cancer de \\ Montpellier, Montpellier Cedex 5 34298, \\ France; ${ }^{2}$ Department of Pathology, \\ Institut Régional du Cancer de \\ Montpellier, Montpellier Cedex 534298 , \\ France; ${ }^{3}$ INSERM UII 94 - Institut de \\ Recherche en Cancérologie de \\ Montpellier (IRCM), Montpellier, France; \\ ${ }^{4}$ University of Montpellier, Montpellier, \\ France; ${ }^{5}$ Department of Surgery, Institut \\ Régional du Cancer de Montpellier, \\ Montpellier Cedex 5 34298, France; \\ ${ }^{6}$ Department of Radiation Oncology, \\ Institut Régional du Cancer de \\ Montpellier, Montpellier Cedex 5 34298, \\ France
}

Correspondence: Marie Alexandre Medical Oncology Department, Institut Régional du Cancer Montpellier, 208, Rue des Apothicaires, Montpellier Cedex 5 34298, France

Tel +33-467 6I 2393

Fax +33-4 67613764

Email marie.alexandre@icm.unicancer.fr

\begin{abstract}
The decision to administer adjuvant chemotherapy in treatment of early invasive breast cancer $(\mathrm{EBC})$ is often complex, particularly for hormone receptor-positive $(\mathrm{HR}+)$ diseases, and current guidelines often classify these patients in an intermediate-risk group. Several biomarkers are currently available in this indication, in order to obtain additional and more accurate prognostic information compared to classic clinicopathological characteristics and guide the indication of adjuvant chemotherapy, optimizing the efficacy/toxicity ratio. We conducted a systematic review to evaluate the clinical validity and clinical utility of five biomarkers (uPA/PAI-1, OncotypeDX ${ }^{\mathbb{R}}$, MammaPrint ${ }^{\circledR}$, PAM50, and EndoPredict ${ }^{\mathbb{R}}$ ) in HR +/HER2- EBC, whatever the nodal status. A total of 89 studies met the inclusion criteria. Even though data currently available confirm the clinical validity of these biomarkers, there is a lack of data regarding clinical utility for most of them. Prospective studies in welldefined populations are needed to integrate these biomarkers in a decision strategy.
\end{abstract}

Keywords: breast cancer, adjuvant chemotherapy, biomarkers

\section{Introduction}

Adjuvant chemotherapy for early breast cancer was shown to improve patients' prognosis and reduce by one-third the 10 -year mortality rate. ${ }^{1}$ This benefit is reported regardless of age, nodal status, tumor differentiation, tumor size, estrogen receptor (ER) status, and use of adjuvant tamoxifen. It has led to the recommendation of adjuvant chemotherapy for most patients with an improvement of both disease-free (DFS) and overall survival (OS). ${ }^{2,3}$ Guidelines recommend chemotherapy for most patients and this can lead to overtreatment. ${ }^{4}$ An important issue is to find tools to determine whether the treatment's benefit outweighs its toxicity.

Clinicopathological criteria such as age, tumor size, nodal status, histological grade, vascular invasion, and ER, progesterone receptor (PR), and human epidermal growth factor receptor 2 (HER2) statuses are commonly used. Informatics tools, such as Adjuvant! Online ${ }^{5,6}$ or Predict, ${ }^{7}$ have been developed and validated to integrate these data and give an evaluation of the risk of recurrence.

Subsequently, prognostic and predictive biomarkers have been developed to help clinicians adjust treatment decisions. The aim of this systematic review is to describe the prognostic and predictive values of several biomarkers which currently have the most advanced development in case of HR+ and HER2-negative (HER2-) early invasive breast cancer in order to help clinician decisions. 
The development of several biomarkers relies on the molecular classification of breast cancers. The first molecular classification, based on gene expression using DNA microarrays, was developed by Perou et al in 2000 and has led to the identification of 4 subtypes of invasive breast cancer: basallike, HER2-enriched, luminal A, and luminal B. ${ }^{8,9}$ Each subtype was associated with different immunohistochemical (IHC) profiles and clinical outcomes. ${ }^{9}$ The use of this molecular classification is however limited by the cost, the complexity of microarray analysis of thousands of genes, and the need for fresh frozen tissue. Moreover, about $30 \%$ of the tumors do not belong to any of the previously described subtypes ${ }^{10}$ and the identification of new subtypes is currently being worked on. ${ }^{11}$

Due to the concordance of gene expression and IHC profiles, new IHC techniques have subsequently been developed. The 2011 St Gallen Breast Cancer Conference Expert Panel proposed to use clinicopathological criteria to evaluate the gene expression-based classification and then allow its use in clinical practice. ${ }^{12}$

However, the IHC-based and the gene expression profiles-based classifications are not overlapping. The agreement rates for patient classification were of $73 \%$ to $100 \%$ for the luminal subtype, of $41 \%$ to $69 \%$ for the HER2enriched subtype, and of about $80 \%$ for the basal-like subtype. $^{13}$

Several commercial genomic tests are currently available for breast cancer. In this review, we studied first-generation signatures such as the 21-gene recurrence score (Oncotype $\mathrm{DX}^{\circledR}$ ) and the 70 -gene signature (MammaPrint ${ }^{\circledR}$ ), as well as second-generation signatures such as the PAM50 risk of recurrence $\left(\right.$ Prosigna $\left.^{\mathbb{B}}\right)$ and the 11-gene assay (EndoPredict ${ }^{\mathbb{R}}$ ). We also focused on the association of urokinase plasminogen activator and plasminogen activator inhibitor type 1 (uPA/ PAI-1), a signature with an IA level of evidence (LOE) included in the ASCO recommendations ${ }^{14}$ in the same setting.

\section{Methods}

\section{Population}

We focused our study on HR+ HER2- patients with early breast cancer, whatever the nodal status. Indeed, it is in these patients that the decision of adjuvant chemotherapy is the most difficult to take, with a frequent intermediate risk of relapse according to usual guidelines, and therefore the interest of biomarkers is the greatest.

\section{Biomarkers}

We chose to focus on the following biomarkers: UPA/PAI-1, the 21-gene recurrence score (Oncotype $\mathrm{DX}^{\circledR}$ ), the 70-gene signature (MammaPrint $\left.{ }^{\circledR}\right)$, the 11-gene assay $\left(\right.$ EndoPredict $\left.^{\circledR}\right)$, and PAM50 (Prosigna ${ }^{\circledR}$ ) because their level of evidence is the highest.

\section{Systematic Search}

We searched the MEDLINE database, using the following terms: (i) for uPA/PAI-1: "breast cancer" and "uPA/ PAI-1" or "urokinase plasminogen activator" or "plasminogen activator inhibitor", (ii) for Oncotype $\mathrm{DX}^{\mathbb{B}}$ : "breast cancer" and "Oncotype DX" or "recurrence score" or "21-gene recurrence score", (iii) for Mamma Print $^{\circledR}$ : "breast cancer" and "MammaPrint" or "70-gene signature", (iv) for EndoPredict ${ }^{\circledR}$ : "breast cancer" and "EndoPredict" or "11-gene assay", (v) for PAM50: "breast cancer" and "PAM50" or "Prosigna" or "single sample predictor" or "single sample predictors" or "50gene subtype predictor".

We only considered English language and peerreviewed published articles. Initial results were reviewed and cross-referenced to ensure that all eligible studies were captured. The following publications were excluded: nonrelevant title or abstract, systematic reviews, case reports, publications which did not include a survival endpoint (except in neoadjuvant setting, in which we included articles with results on tumor response), only HR-negative (HR-) or HER2-positive (HER2+) tumors, metastatic breast cancer.

If the population was the same in several articles, we considered the study published first.

For uPA/PAi-1, we only considered the studies which evaluated the association of UPA and PAI- 1 and not those evaluating only one of them or the two separately.

For PAM50, we only considered the studies which evaluated the risk or recurrence (ROR) and not those only evaluating the classification into subtypes according to PAM50.

\section{Evaluation}

We evaluated each biomarker according to the principles of the Evaluation of Genomic Application in Practice and Prevention (EGAPP) Initiative ${ }^{15}$ which defined for each test: 
- the clinical validity, i.e., the ability of the test to accurately and reliably identify or predict a relevant breast cancer survival endpoint;

- the clinical utility, i.e., the ability of the test to guide treatment decision to improve the clinical outcome.

On the basis of our systematic search, we retrieved information about clinical validity. In the selected studies, we identified the multivariate models and listed them in tables. To avoid bias, we only selected, for the multivariate models analysis, the studies with the largest population among the studies with overlapping populations (similar datasets, for example). If more than one model was carried out in the same study to test different endpoints, we considered the one that was specified as the primary endpoint except if several endpoints were pre-specified.

To assess the clinical utility of the biomarkers, we selected prospective studies. We also looked clinical.trial. gov for the ongoing studies.

In each study, we searched whether invasive lobular carcinomas (ILC) were listed. If they were, we looked to see if the results of the biomarker were different to determine the potential interest of given biomarker in this specific histological subtype.

Furthermore, we checked the latest recommendations of the French National Cancer Institute (INCa) ${ }^{16}$ and the ASCO recommendations ${ }^{14}$ about these biomarkers. In the recommendations, the LOE is evaluated for each biomarker. In 1996, Hayes et al ${ }^{17}$ described a method to evaluate tumor markers clinical utility and give LOEs for the tumor markers prognostic and predictive values, which was validated by an ASCO committee. In 2009, Simon et al ${ }^{18}$ updated these levels with a new LOE, IB, including retrospective studies using archived biomarkers samples which had been collected prospectively.

\section{Results}

\section{Eligible Studies}

The results of our systematic search and the selection of articles included in the present study are described in Figure 1. We selected 16 studies for uPA/PAI-1, 31 studies for Oncotype DX ${ }^{\circledR}, 21$ studies for MammaPrint ${ }^{\circledR}, 6$ studies for EndoPredict ${ }^{\circledR}$, and 15 studies for PAM50. Among them, very few included specifically patients with HR+,

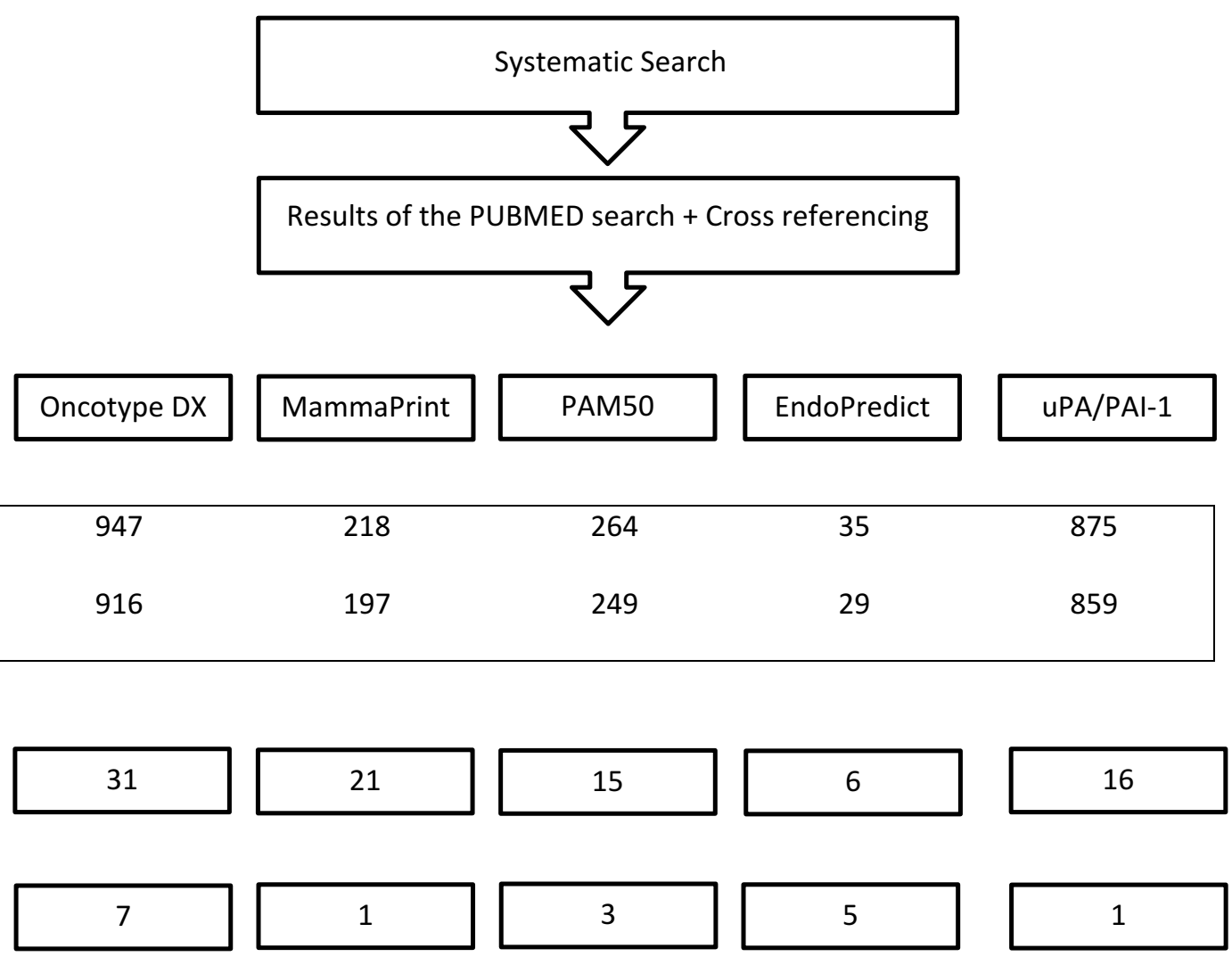

Figure I Flowchart of eligible studies. 
HER2- tumors: 1 for uPA/PAI-1, 7 for Oncotype DX ${ }^{\circledR}, 1$ for Mammaprint ${ }^{\circledR}, 5$ for EndoPredict ${ }^{\circledR}$, and 3 for PAM50.

\section{uPA/PAI- I}

\section{Introduction}

uPA and PAI-1 are proteases involved in tissue stroma reaction which participate in plasminogen activation and thus promotes invasion and metastasis. They interact with a lot of key cell signaling pathways and affects cell adhesion, migration, proliferation, and survival. ${ }^{19}$ The uPA/ PAI-1 complex has been involved in many types of cancers $^{20}$ and its prognostic value has been best studied in breast cancer. Duffy et al published the first article which described a poorer disease-free survival (DFS) in case of high level of uPA in tumor tissue. ${ }^{21}$ Jänicke et al confirmed the negative prognostic value in terms of DFS and overall survival (OS) for UPA and PAI-1 considered independently. $^{22}$ UPA and PAI-1 levels are determined using the ELISA technique, from 80 to $100 \mathrm{mg}$ of frozen tissue, limiting its use in case of tumors bigger than $1 \mathrm{~cm} .^{23}$ It can be performed in local centers.

Two studies described below validated these biomarkers at a LOE I. ${ }^{24,25}$

\section{Clinical Validity}

\section{Prognostic Value}

In a prospective trial including 556 patients with nodenegative ( $\mathrm{pN} 0$ ) tumors, patients with low uPA/PAI-1 levels did not receive any adjuvant chemotherapy while patients with high uPA/PAI-1 levels were randomized between chemotherapy or not (the "Chemo N0" trial). ${ }^{24}$ Chemotherapy consisted of CMF (cyclophosphamide, methotrexate, fluorouracil). In the group without chemotherapy, the 3-year DFS rate was longer in the low-risk group (93.3\% versus $85.4 \%$ in the high-risk group, $\mathrm{RR}=2.71, p=0.009){ }^{24}$ The 10 -year analysis confirmed these results (10-year DFS rate of $87.1 \%$ in the low-risk group versus $77.0 \%$ in the highrisk group $[p=0.011]){ }^{26}$

A pooled-analysis in 8377 individual patients ( $\mathrm{pN} 0$ and $\mathrm{pN}+$ ), performed by members of the European Organization for Research and Treatment of Cancer-Receptor and Biomarker Group (EORTC-RBG), showed a difference in terms of DFS and OS according to the uPA and PAI-1 levels. $^{25}$ In multivariate analysis, levels of uPA and PAI-1 combined together were the second stronger prognostic factors, after lymph node status. At 10 years, the difference between patients with a favorable prognosis and patients with an unfavorable prognosis, defined by a score taking into account uPA and PAI-1 levels, was $28.2 \%$ for OS and $34.5 \%$ for DFS. Also, in both $\mathrm{pN} 0$ and $\mathrm{pN}+$ patients, higher uPA and PAI-1 values were independently associated with poor RFS and poor OS.

Unfortunately, these 2 large studies included patients with both $\mathrm{HR}+$ and HR- tumors.

Other retrospective studies, mostly in pN0 patients, most of them with ER+ tumors, also found a similar prognostic value. However, studies considered different and heterogeneous populations in terms of ER, nodal, or HER2 status, type of systemic treatment, and they used different cut-offs for uPA/PAI-1 levels (Table S1 in supplementary data). Only one retrospective study ${ }^{27}$ considered only our target population $\mathrm{HR}+$, HER2- and found no significant difference in RFS or OS in high-risk and lowrisk groups (but patients with low uPA/pAI-1 had less chemotherapy). The multivariate models in adjuvant studies evaluating uPA/PAI-1 (as well as other signatures) are detailed in Table S6 in supplementary data.

\section{Predictive Value}

In the Chemo N0 trial, patients with high uPA/PAI-1 levels were included in a randomized controlled open-label phase III trial to evaluate the efficacy of CMF adjuvant chemotherapy. At 10 years, DFS was higher for patients treated with chemotherapy in the high-risk group $(78.7 \%$ vs $67.9 \%$ without chemotherapy, $\mathrm{HR}=0.48, p=0.019)$. The estimated hazard ratio for the ITT population showed a benefit of $\mathrm{CMF}(\mathrm{HR}=0.74,95 \% \mathrm{CI}=0.44-1.27)$, but the difference was not statistically significant $(p=0.278) .^{26}$ In per-protocol analysis, the adjusted hazard ratio was 0.48 (95\% CI=0.26-0.88), in favor of CMF $(p=0.019){ }^{26}$ Anyway, results are now less impactful as CMF chemotherapy is no longer a standard of care.

In the same line as this randomized trial, retrospective studies suggested a predictive value of the uPA/PAI-1 level with response to chemotherapy ${ }^{28}$ and a better response to anthracycline-based chemotherapy as opposed to $\mathrm{CMF}^{29}$ However, as for prognostic value, the studies included a diverse population with ER-tumors, and HER2 status was mostly not reported.

\section{Clinical Utility}

The NNBC3 ("Node Negative Breast Cancer 3 - Europe") trial was a multicenter, randomized, open-label phase III trial which included 4149 pN0 patients. It was designed to compare the risk assessment with traditional clinicopathological factors and with a biological algorithm based on the uPA/ 
PAI-1 levels. Each participating center decided upfront the type of risk assessment for all of its patients. Patients in the high-risk group were randomized between an anthracyclinebased $($ FEC $\times 6$ cycles $)$ or anthracycline and taxane-based chemotherapy $($ FEC $\times 3$ and docetaxel $\times 3)$. Recruitment was closed in December 2008 and results are expected shortly. ${ }^{30}$

This study has limitations preventing showing uPA/ PAI-1 clinical utility: the lack of randomization between the types of risk assessment selected by each center; which induced a selection bias; inclusion of patients with HER2+ tumors; also, the sample size was calculated to detect a difference in efficacy between the two chemotherapy regimens and it was not designed to assess the real benefit of taking uPA/PAI-1 into account in the treatment decision.

\section{Recommendations and Conclusions}

The INCa (Institut National du CAncer, French National Cancer Institute) recommendations attributed a IA LOE for the prognostic value of UPA/PAI-1, a IA LOE for its predictive value of response to CMF-based chemotherapy, and a IIIC level for anthracyclines-based chemotherapy. ${ }^{16}$

According to the ASCO recommendations, clinicians may use uPA/PAI-1 to guide their decisions on adjuvant systemic chemotherapy in ER/PR positive, HER2 negative, and pN0 breast cancers. However, the strength of these recommendations is weak because of the lack of evidence for uPA/PA-1 use in a contemporary treatment setting, ${ }^{14}$ as highlighted earlier.

The main issue remains the definition of the population of interest, which was not especially targeted in the described studies due to their period of inclusion. Even if this biomarker undoubtfully has assets (can easily be performed in local centers, with a modest cost and binary results), it remains today difficult to conclude about utility of UPA/PAI-1 for patients with ER+, HER2- tumors.

\section{Oncotype DX ${ }^{\circledR}$ (Table I)}

\section{Introduction}

The Oncotype $\mathrm{DX}^{\circledR}$ uses a quantitative reverse transcription polymerase chain reaction (qRT-PCR) assay in FFPE tumor samples to evaluate the level of expression of 21 genes (16 cancer-related genes and 5 reference genes). ${ }^{31}$ They were selected among 250 candidate genes after a literature review, using statistical analysis and modelization, and mainly correspond to proliferation genes. A Recurrence Score (RS) was calculated using an algorithm according to their levels of expression. The RS, score from 1 to 100 , is a continuous variable estimating the 10-year risk of recurrence under adjuvant hormonal treatment, without chemotherapy. Patients are categorized into three groups: low RS $(<18)$, intermediate RS (18-31), and high RS (>31).

The score was developed in patients with ER+ pN0 disease treated with tamoxifen. ${ }^{31}$ It was performed in a central laboratory (Genomic Health) and proved analytical validity in an intra laboratory validation. ${ }^{32,33}$

\section{Clinical Validity}

\section{Prognostic Value}

Several retrospective studies using archived samples from prospective studies found a difference of DFS between the 3 RS groups in a large population of ER+ patients $(n=3382)$, $\mathrm{pN} 0^{31,34-36}$ or $\mathrm{pN}+.^{37-39}$ Other retrospective studies found similar results in a mostly ER+ population ${ }^{40-45}$ (Table S2, in supplementary data). Most studies showed a significant association between Oncotype $\mathrm{DX}^{\circledR}$ and breast cancer outcome: in ER+ pN0 patients without systemic treatment, ${ }^{46}$ in ER+ pN0 patients treated with ET alone, ${ }^{31,36,40,42,44-47}$ and in patients treated with chemotherapy and ET. ${ }^{34,41,43,46,48}$ An association between the RS and patients' outcome was also found in $\mathrm{ER}+\mathrm{pN}+$ patients. $^{35,36,41,43,44,49,50}$ Only three retrospective studies evaluated the Oncotype $\mathrm{DX}^{\circledR}$ in the target population of strictly ER+, HER2- patients. $^{51-53}$ In studies including only HR+, HER2- tumors, two studies evaluated Oncotype DX ${ }^{\circledR}$ in multivariate model and only one found it to be an independent prognostic factor (Table 2A).

Long-term data of the transATAC (Arimidex Tamoxifen Alone or in Combination) cohort study indicated that Oncotype $\mathrm{DX}^{\circledR}$ had a better prognostic value during the first 5 years than later on (between 5 and 10 years) both in the whole population ${ }^{54}\left(\chi^{2}=5.55\right.$ and $p=0.02$ after 5 years in multivariate analysis) and in the $\mathrm{pN} 0$ population $^{55}(\mathrm{HR}=1.13$ and $p=0.47$ after 5 years in multivariate analysis). Similarly, the RS was no longer prognostic after 5 years in the study of Albain et al. ${ }^{49}$

Once again, the prognostic value of Oncotype Dx was found in studies which did not include only our target population, leading to potential bias of selection.

\section{Predictive Value}

Among these studies, two suggested a predictive value of the $\mathrm{RS}$ in a retrospective analysis of subsets of patients from prospective trials: both $\mathrm{pN} 0^{34}$ or $\mathrm{pN}+{ }^{49}$ patients with a high RS seemed to benefit from chemotherapy. Patients with ER+ pN0 tumor and a high RS had a 10-year DMFS rate of $60.5 \%$ when treated with ET alone and 88.1\% when treated with ET 


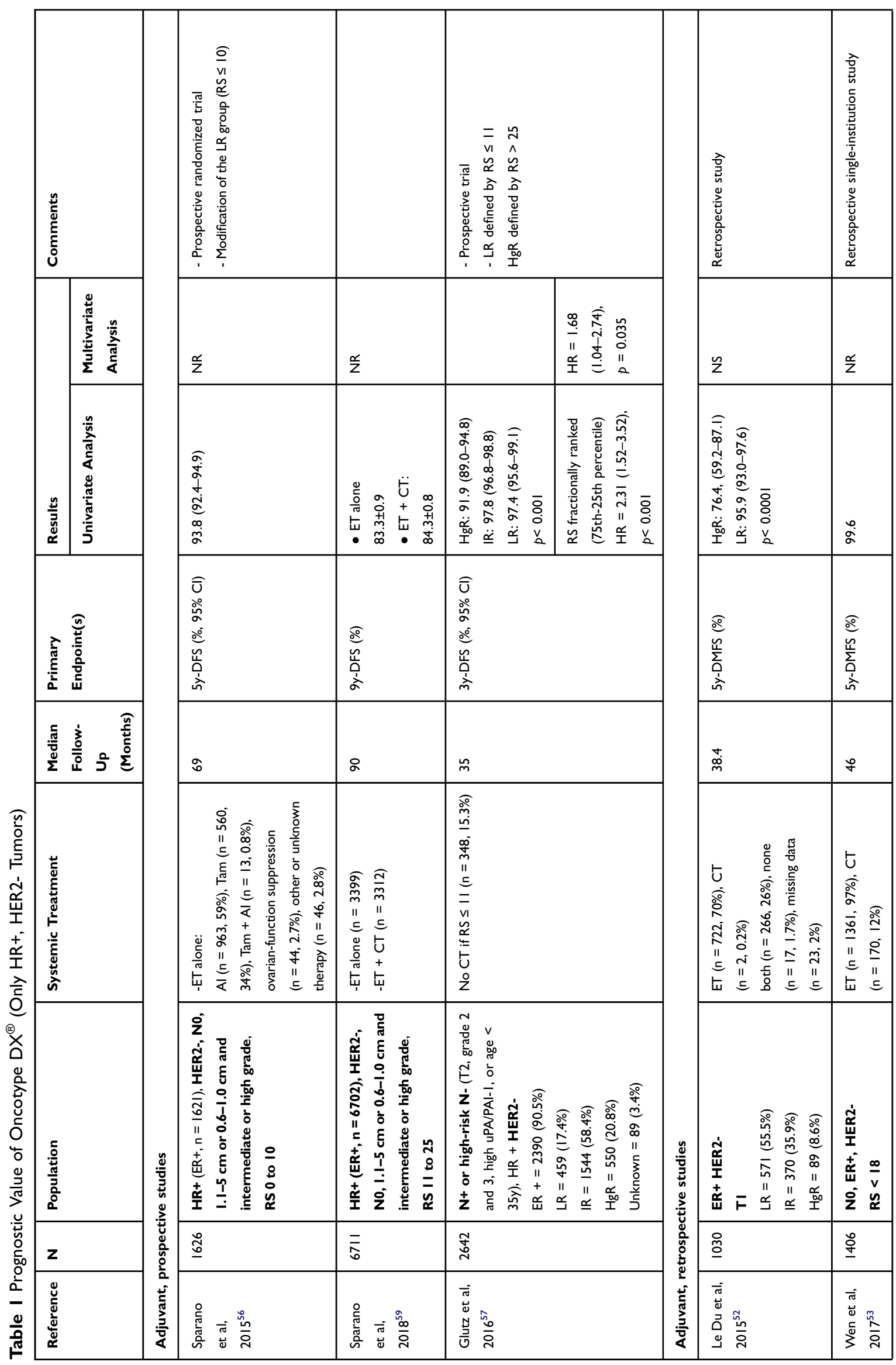




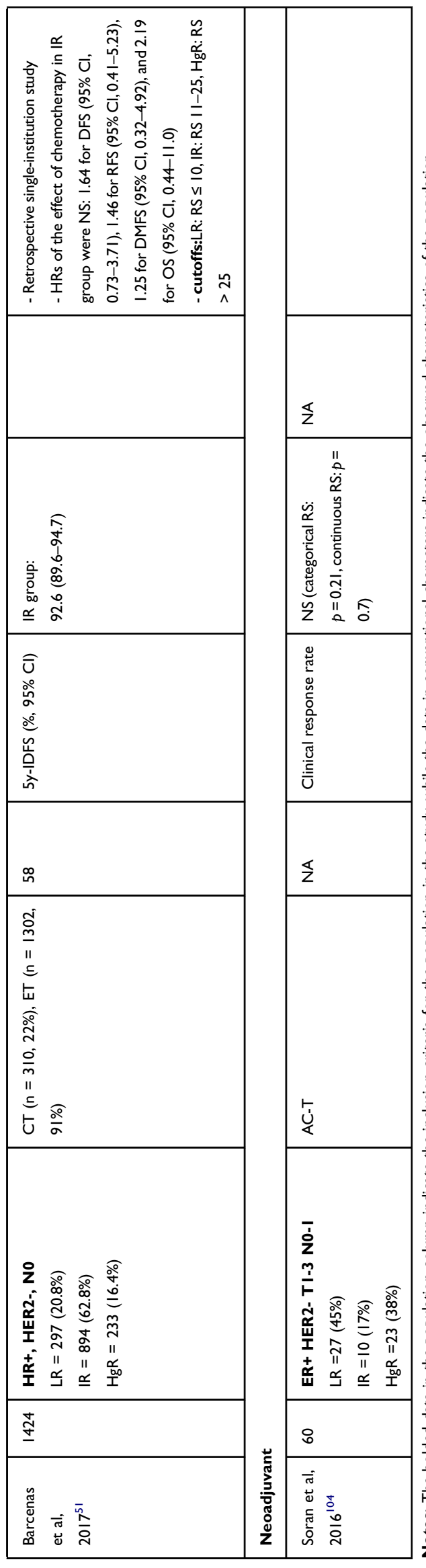

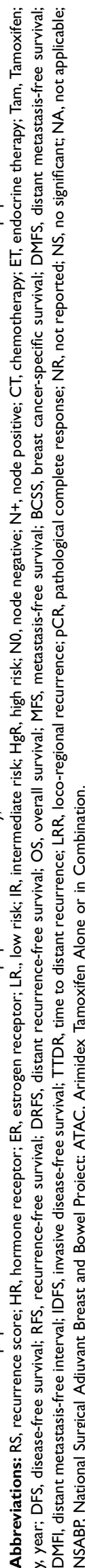

Table 2 Evaluable Multivariate Analysis of Biomarkers for Prognosis in Adjuvant Studies in HR+, HER2- Patient

\begin{tabular}{|c|c|}
\hline \multicolumn{2}{|l|}{ A. Oncotype DX ${ }^{\circledR}$} \\
\hline \multicolumn{2}{|l|}{ Number of unique patients } \\
\hline Total & 3672 \\
\hline Number of multivariate models & 2 \\
\hline Biomarker is significant $(p<0.05)$ & I \\
\hline \multicolumn{2}{|l|}{ Adjustment factors (\%) } \\
\hline - Tumor grade & $100 \%$ \\
\hline - Tumor size & $50 \%$ \\
\hline - Nodal status/number of nodes & $50 \%$ \\
\hline - ER level & $50 \%$ \\
\hline - PR level & $50 \%$ \\
\hline - Ki-67 & $100 \%$ \\
\hline
\end{tabular}

B. EndoPredict ${ }^{\circledR}$

Number of unique patients

\begin{tabular}{|l|l|}
\hline Total & 4509 \\
\hline Number of multivariate models & 4 \\
\hline Biomarker is significant $(p<0.05)$ & 4 \\
\hline Adjustment factor $(\%)$ & \\
- Tumor size & $100 \%$ \\
- Nodal status/number of nodes & $100 \%$ \\
- Tumor grade & $100 \%$ \\
- Age & $100 \%$ \\
- ER status & $25 \%$ \\
- PR status & $50 \%$ \\
- Ki-67 & $50 \%$ \\
- Type of endocrine therapy & $75 \%$ \\
- Systemic treatment & $25 \%$ \\
\hline
\end{tabular}

and chemotherapy $(\mathrm{RR}=0.26,95 \% \mathrm{CI} 0.13-0.53) .{ }^{34}$ On the contrary, in patients with a low RS, the 10-year DMFS rates were not significantly different for patients treated with ET alone (96.8\%) or with ET and chemotherapy (95.6\%). The interaction between the RS and chemotherapy benefit was statistically significant $(p=0.038) .{ }^{34}$ Unfortunately, HER2 status was not reported in this trial. In postmenopausal patients with $\mathrm{HR}+\mathrm{pN}+$ tumor and a high $\mathrm{RS}$, the 10-year DFS rates were $43 \%$ when treated with ET alone and 55\% when treated with ET and chemotherapy $(p=0.033$, $\mathrm{HR}=0.59,95 \%$ CI $0.35-1.01){ }^{49}$ There was no benefit of chemotherapy for the patients with a low RS, who had 10year DFS rates of $60 \%$ when treated with ET alone and $64 \%$ when treated with ET and chemotherapy ( $p=0.97, \mathrm{HR}=1.02$, 95\% CI 0.54-1.93). The interaction of treatment benefit and 
RS was significant, adjusting for age, race, tumor size, PR status, grade, p53 and HER2 status, but not with adjustment for $\operatorname{ER}$ level $(p=0.15){ }^{49}$

\section{Clinical Utility}

Two prospective trials (the TAILORx trial - Trial Assigning Individualized Options for Treatment- ${ }^{56}$ and the Phase III PlanB West German Study Group Trial ${ }^{57}$ ) found excellent DFS rates of, respectively, $93.8 \%$ at 5 years and $97.4 \%$ at 3 years in the low-risk group without chemotherapy. The cut-off set-up in these trials for the low-risk group was lower than previously described $(\leq 10$ in TAILORx and $\leq 11$ in the PlanB trial).

TAILORx included women with $\mathrm{HR}+(\mathrm{ER}+$ and/or $\mathrm{PR}+)$ HER2- pN0 early breast cancer. Patients had to meet the National Comprehensive Cancer Network guidelines for the recommendation or consideration of adjuvant chemotherapy: tumor of 1.1 to $5.0 \mathrm{~cm}$ of any grade, or of 0.6 to $1.0 \mathrm{~cm}$ and intermediate or high histologic grade or nuclear grade or both. All patients underwent determination of their tumor's RS by Oncotype DX ${ }^{\circledR}$. Patients with a 0 to 10 score were assigned to receive ET alone and those with a score of 26 or higher were assigned to receive chemotherapy plus ET. Patients with a score of 11 to 25 were randomized between the two groups (ET alone or chemotherapy plus ET). To minimize the risk of patients' undertreatment, the cut-off for the low-risk group was set up lower than previously described ( $\leq 10$ vs 18 in the original definition ${ }^{58}$ ).

The results of the low-risk group were published in $2015 .^{56}$ The cohort included 1626 patients $(15.9 \%$ of the whole population of 10,253 patients) who presented several factors of good prognosis: tumors were $<2.0 \mathrm{~cm}$ and $<3.0 \mathrm{~cm}$ in $69 \%$ and $92 \%$ of the cases, respectively; $98 \%$ of the tumors were PR+ and only 7\% had a high histological grade. After a median follow-up of 69 months, the invasive disease-free survival rate at 5 years (primary endpoint) was $93.8 \%$ (95\% CI 92.4-94.9), the rate of freedom from recurrence of breast cancer at a distant site at 5 years was 99.3\% (95\% CI 98.7-99.6), the rate of freedom from recurrence at 5 years was 98.7\% (95\% CI 97.9-99.2), and 5-year OS rate was 98.0\% (95\% CI 97.1-98.6). The low rate of distant recurrence was consistent with the 5-year rate observed in the original validation study ${ }^{31,58}$ with a cut-off of $18(2.1 \%, 95 \%$ CI $0.6-3.7)$. It should be noted that the distribution of RS differed from the distribution of the prior prospective-retrospective validation study which included $27 \%$ of the patients with a score of 0 to 10 (43\% with a score of 11 to 25 and $30 \%$ with a score $\geq 26) .{ }^{34,56}$ From a statistical point of view, there was no specific enrollment objective for the low-risk group, but the authors estimated that the large sample provided the opportunity to estimate 5-year event rates accurately. Moreover, no detail was provided regarding $\mathrm{Ki67}$, the mitotic index, histology, perivascular invasion or the intensity of staining for HR, all these factors being well-known predictive and/or prognostic factors used in clinical routine decision-making. Thus, these prospective data confirm the prognostic value of Oncotype DX ${ }^{\circledR}$ and the ability of this test to identify patients with a very low risk of recurrence and who will not benefit from adjuvant chemotherapy. However, these data, to date, do not confirm the clinical utility of this test and its added value to clinicopathological data.

The benefit of adjuvant chemotherapy for patients with intermediate RS remained unclear and was investigated in this trial. Patients with an RS of 11-25 were randomized between chemotherapy plus ET vs ET alone. The results were published in 2018. ${ }^{59}$ Among 6711 patients with an RS of 11 to 25,3399 were randomly assigned to receive ET alone and 3312 to receive chemotherapy and ET. The 9-year DFS rates were $83.3 \%$ in the ET group and $84.3 \%$ in the chemotherapy plus ET group. Statistically, ET was noninferior to the association of chemotherapy and ET with an HR of 1.08 (95\% CI 0.94-1.24, $p=0.26)$. In the exploratory analyses of subgroups, in younger women ( $\leq 50$ years), chemotherapy was associated with a lower rate of distant recurrence than ET alone, suggesting they may benefit more from this chemotherapy than older women. This is a clinical data that was already known and used to guide decision of adjuvant chemotherapy. Interestingly, they estimated that $73.9 \%$ of the patients with an RS between 11 and 25 were already at low clinical risk. For these patients, there is so no evidence that Oncotype $\mathrm{DX}^{\circledR}$ provides additional information to clinical data. Furthermore, all the patients with a high RS were assigned to receive chemotherapy. Among them, 43\% $(n=1359)$ were at low clinical risk: the test may lead to overtreatment without showing its superiority to the clinical estimation of the risk.

The TAILORx trial had several limits. First, the selected population was at very low risk of recurrence according to clinicopathological data: this population does not match the population in which we question the benefit of chemotherapy and this may lead to overtreatment. Adjuvant! Online already showed a low benefit of chemotherapy for these patients. Second, its design did not 
compare a strategy with and without the genomic test: they did not show that Oncotype $\mathrm{DX}^{\circledR}$ brought more information than clinicopathological data. Moreover, a lot of them were not described (Ki67, the mitotic index, histology, perivascular invasion or the intensity of staining for HR), precluding the precise definition of risk in this tested population. The additional contribution of the genomic test is therefore questionable. In addition, patients in the low- and high-risk groups should theoretically have been randomized between chemotherapy and non-chemotherapy to demonstrate clinical utility. Finally, repeated changes in thresholds can lead to confusion in the interpretation of test results, especially since they challenge a new agespecific threshold that is not justified by previous studies. Moreover, the registry used to justify the new TAILORx thresholds included patients who were different from the trial (at higher risk in the registry). There was therefore a real problem in defining the target population.

Secondary analyses of the TAILORx trial ${ }^{60}$ confirmed the prognostic importance of clinical criteria (tumor size, grade, and age). A clinical risk based on the Adjuvant! Algorithm was prognostic of distant recurrence in patients with an intermediate RS who received ET alone (HR 2.73; 95\% CI 1.93-3.87), in patients with intermediate RS who received chemotherapy and ET (HR 2.41; 95\% CI 1.66-3.48 ), and in patients with high RS (HR 3.17; 95\% CI 1.94-5.19). It underlines the necessity to take clinical factors into account for the evaluation of patients' prognosis and treatment decision.

The results from the translational research program of the prospective randomized multicenter PlanB trial have recently been published. ${ }^{57}$ In this trial, 3198 patients with early HR+ HER2- breast cancer were enrolled: $41.1 \%$ had $\mathrm{pN}+$ and $32.5 \%$ had grade 3 tumors. PlanB was initiated to compare an anthracycline-containing regimen and an anthracycline-free regimen as adjuvant chemotherapy. After an early amendment (and inclusion of 274 patients), patients with an $\mathrm{RS} \leq 11$ were recommended not to receive chemotherapy. In 348 patients $(15.3 \%$ of the patients, $31.4 \% \mathrm{pN}+$ and $20 \%$ grade 3 ), the $\mathrm{RS}$ was $\leq 11$. After a 35 month median follow-up, the 3 -year DFS rate was $98 \%$ in this subgroup (vs 92\% in patients with an RS > 25 and $98 \%$ in patients with an RS between 12 and 25, all treated with chemotherapy). Interestingly, in the whole population, only $5.8 \%$ of the patients with grade 3 tumors had a low RS $(\leq 11)$ and all patients in the small group with $\mathrm{Ki} 67 \geq 40 \%$ and $\mathrm{PR} \leq 20$ had an $\mathrm{RS}>25$. In multivariate analysis, the nodal status, local grade, central grade, and
RS were independent prognostic factors. Overall, these prospective data confirmed the prognostic value of Oncotype $\mathrm{DX}^{\circledR}$ and the ability of this test to identify patients with a very low risk of recurrence both in pN0 and $\mathrm{pN}+$ tumors. However, a longer follow-up is required to confirm these results.

Moreover, the RxPONDER ( $\mathrm{Rx}$ for Positive NoDe, Endocrine Responsive; ClinicalTrials.gov identifier: NCT01272037) trial was designed to assess the clinical utility of the test in patients with one to three positive nodes: if the RS was $<25$, patients were randomly assigned between ET with chemotherapy and ET alone. The study is still recruiting.

\section{Recommendations and Conclusions}

Based on three prospective studies using archived samples, the INCa recommendations attributed a IIB LOE to the prognostic value of Oncotype $\mathrm{DX}^{\circledR}$ in $\mathrm{ER}+\mathrm{pN} 0$ or $\mathrm{pN}+$ breast cancer. They did not consider level IB because of the lack of representativeness of the studied samples (according to Simon's guidelines, at least two-thirds of the population from the prospective trial must be included in the cohort of analysis to justify this LOE). Its predictive value was estimated to be II LOE for the response to chemotherapy with CMF or anthracyclines and IIIC LOE for the response to ET. They additionally pointed the lack of external analytical validation and the correlation with usual markers. $^{16}$

According to the ASCO recommendations, the Oncotype $\mathrm{DX}^{\circledR}$ test may be used to determine adjuvant chemotherapy in ER/PR positive HER2- pN0 breast cancers with a IB LOE. In case of low RS, chemotherapy was not recommended and in case of high RS, chemotherapy was recommended. For patients with intermediate RS, the results cannot currently be used to establish chemotherapy. In case of $\mathrm{pN}+$ breast cancer, they did not recommend the test to guide the treatment decision because of the potential benefit of chemotherapy in this subgroup (IIB LOE). ${ }^{14}$

To conclude, prospective data confirmed the prognostic value of Oncotype $\mathrm{DX}^{\circledR}$ and the ability of this test to identify patients with a very low risk of recurrence. However, we have previously detailed the main limitations of the TAILORx study to demonstrate clinical utility (a very low-risk study population, repeated threshold changes and poor design for demonstrating clinical utility). 


\section{Mammaprint $^{\circledR}$} Introduction

The Mammaprint ${ }^{\circledR}$ test initially used DNA microarrays on fresh-frozen tissues. Seventy genes involved in proliferation, invasion, angiogenesis, and metastasis were identified in women $<55$ years with N0 tumors $<5 \mathrm{~cm}$, without any adjuvant treatment. It classified patients into two groups, patients of good or poor prognosis, on the basis of the distant recurrence risk at 5 and 10 years. ${ }^{37}$ It was then developed on FFPE tissue. ${ }^{38}$

The test has been shown to be highly reproducible both intra- and inter-laboratory. ${ }^{39,61}$ It is now centralized and commercialized by Agendia (Amsterdam).

\section{Clinical Validity}

Prognostic Value

Most of the retrospective studies found a prognostic value for MammaPrint ${ }^{\circledR}$ in addition to clinicopathological factors in different populations ( $\mathrm{pN} 0$ or $\mathrm{pN}+, \mathrm{ER}+$ or ER-, HER2+ or HE2- tumors in pre- or postmenopausal women) $)^{39,41,62-65}$ as described in Table S3 in Supplementary data. The poor prognostic group represented about $60 \%$ of the whole population. None of these studies consider exclusively our target population of $\mathrm{HR}+$, HER2- tumors.

Long-term data seemed to indicate a better prognostic value during the first 5 years after diagnosis and found non-significant hazard ratios for DMFS after 5 years. ${ }^{64,66}$

\section{Predictive Value}

In neoadjuvant trials with chemotherapy, the poor prognosis group had a higher rate of pCR, suggesting the predictive value of this test. ${ }^{67-69}$ In the only study considering only HR+, HER2- tumors, Mammaprint ${ }^{\circledR}$ was not shown to be an independent predictive factor of pCR. ${ }^{69}$

\section{Clinical Utility}

The Microarray In Node-negative and 1 to 3 Positive Lymph Node Disease may Avoid ChemoTherapy (MINDACT) $\operatorname{trial}^{70}$ was a prospective randomized trial including 6693 women with $\mathrm{pN} 0$ or $\mathrm{pN}+$ (up to 3 nodes), and $\mathrm{T} 1, \mathrm{~T} 2$, or operable $\mathrm{T} 3$ tumors.

In the initial study design, all patients had to have pN0 disease, but the protocol was revised after the publication of the study of Mook et $\mathrm{al}^{71}$ and allowed enrolling patients with 1 to 3 positive axillary nodes. They used the 70-gene signature to determine genomic risk and Adjuvant! Online (version 8.0 with HER2 status) to evaluate the clinical risk. A low clinical risk was defined as a 10 -year probability of breast cancer-specific survival (BCSS) without systemic therapy of more than $88 \%$ among patients with ER+ tumors, and of more than $92 \%$ among patients with ERtumors. Women at low clinical and low genomic risk did not receive adjuvant chemotherapy; those with high clinical and high genomic risk did receive such therapy. In case of discordance, either the clinical or the genomic risk was used to determine chemotherapy administration. Factors of stratification were institution, risk group, HR status, nodal involvement, age, HER2 status, axillary treatment, and type of surgery. Additional randomizations were proposed both for chemotherapy (anthracycline-containing regimen or docetaxel plus capecitabine) and ET in case of HR+ tumors (tamoxifen and letrozole or letrozole-only regimen).

Patients were classified into 4 main groups: low clinical and genomic risk ( $\mathrm{n}=2745,41.0 \%$ of the patients), low clinical and high genomic risk $(\mathrm{n}=592,8.8 \%)$, high clinical and low genomic risk $(n=1550,23.2 \%)$, and high clinical and high genomic risk ( $n=1806,27.0 \%)$. Seventy-nine percent of patients had a pN0 disease, $20.9 \%$ had 1 to 3 positive nodes (including micrometastases), $88.4 \%$ expressed ER, PR, or both, and $9.5 \%$ had a HER2+ tumor. The primary analysis was designed to test whether, among patients with high clinical risk and low genomic risk who did not receive chemotherapy, the lower boundary of the $95 \%$ CI for the 5-year survival without distant metastasis rate would be of $92 \%$ (non-inferiority boundary) or higher. Among these 1550 patients, $48 \%$ had a $\mathrm{pN}+$ disease, $93 \%$ had grade 2 or 3 tumors, and $34 \%$ were $\leq 50$ years old. The percentage of patients without distant metastasis at 5 years in this group was $94.7 \%$ (95\% CI 92.5-96.2). Thus, the primary objective of this study was met. Moreover, there was no different outcomes between patients who received chemotherapy and those who did not ( 1.5 points, $\mathrm{HR}=0.78,95 \%$ CI $0.50-1.21$, $p=0.27$ ). Similar results were observed for the subgroup with ER+ HER2- tumors and for patients with a $\mathrm{pN} 0$ or $\mathrm{pN}+$ disease. In the group with a low clinical risk and a high genomic risk, the survival without metastasis rate at 5 years was similar with or without chemotherapy ( $\mathrm{HR}=1.17,95 \%$ CI 0.59 to $2.28, p=0.66$ ). Among all patients with high clinical risk, the use of Mammaprint ${ }^{\circledR}$ would lead to a reduction of $46.2 \%$ of the prescription for chemotherapy. The main group in this study consisted of patients with low clinical risk and low genomic risk (41.0\% of the patients). These patients were affected with a favorable prognosis, with a DMFS of 97.6 (95\% CI 96.9-98.1) at 5 years and an OS of $98.4(95 \%$ CI 97.8-98.9) at 5 years. It seems that the association of the clinical low risk and genomic low risk allows the 
identification of a particularly favorable prognosis group. However, the result of the genomic test does not seem to significantly modify the treatment impact. In addition, considering the natural history of this clinicopathological group, the 5-year analysis needs to be updated in order to identify the possible late recurrences linked to HR+/HER2- tumors.

This study had several limitations: first, the systemic treatments received were not precisely described. Second, the population with low clinical risk and high genomic risk was small to show a difference (592 patients, $8.8 \%$ of the study population). Next, even if the difference was not statistically significant in terms of DMFS in high clinical risk patients, the choice of their statistical thresholds can be criticized. In the clinical high risk and genomic low risk population, in ITT analysis, the chemotherapy group had a 5 y-DMFS of $95.9 \%$ (95\% CI 94.0 to 97.2 ) versus $94.4 \%$ (95\% CI 92.3 to 95.9$)$ in the non-chemotherapy group. This statistically accepted difference seems clinically significant. Finally, some data are missing for the analysis of the results in the high clinical risk and low genomic risk group: the actual treatments received by the patients, the data from the per-protocol analysis. In addition, the number of events was particularly low in this group, which did not make it possible to highlight any difference.

\section{Recommendations and Conclusion}

Before the results of the MINDACT trial, the INCa recommendations attributed a LOE IIIC for the prognostic and predictive values of Mammaprint ${ }^{\circledR}$, based on retrospective studies. They also pointed out the correlation with the usual markers. ${ }^{16}$

The MINDACT trial showed the interest of Mammaprint ${ }^{\circledR}$ in patients with a high clinical risk and a low genomic risk, but the limitations for interpreting its results are detailed earlier.

The ASCO issued updated guidelines after the results of the MINDACT trial: ${ }^{72}$ they considered that Mammaprint ${ }^{\circledR}$ may be used in ER/PR positive, HER2-, $\mathrm{pN} 0$ or $\mathrm{pN}+$ (1 to 3 positive nodes) breast cancer with high clinical risk with a IA LOE. It should not be used in case of low clinical risk because chemotherapy did not improve prognosis even in case of high genomic risk.

\section{Endopredict $^{\circledR}$ (Table 3)}

\section{Introduction}

The Endopredict ${ }^{\circledR}$ test was developed using an RT-PCR method on FFPE tumor tissue. Eleven genes were studied, 8 cancer-related genes and 3 reference genes. Levels of
RNA determined the risk score (Endopredict, EP); the clinical risk score (EPclin) combined levels of RNA with two clinical factors, tumor size and nodal status. Patients were divided into two groups, patients at low and high risk (cutoff points at 5 for EP and 3.3 for EPclin). ${ }^{73}$

The test was developed to predict the likelihood of distant recurrence in postmenopausal patients with ER+ HER2- early breast cancer treated with adjuvant ET. It can reliably be decentralized in local laboratories. ${ }^{74,75}$

\section{Clinical Validity}

\section{Prognostic Value}

Studies using archived samples from prospective trials ${ }^{73,76,77}$ on large populations of patients with ER+ HER2- tumors, treated with ET (with or without chemotherapy) found a significant outcome difference between the low- and highrisk groups in multivariate analysis for EP and EPclin (Table

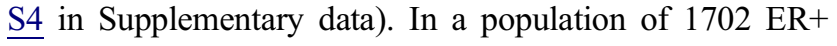
HER2- patients from the ABCSG-6 and the ABCSG- 8 trials, the 10-year DFS was significantly higher in patients with low risk according to the $\mathrm{EP}$ (in multivariate analysis, $\mathrm{HR}=1.19$, IC95\% (1.04-1.36), $p=0.010$ in the ABCSG-6 cohort and $\mathrm{HR}=1.26$, IC95\% (1.15-1.38), $p<0.001$ in the ABCSG-8 cohort). ${ }^{73}$ More than 4500 patients were investigated in 4 multivariate models (Table 2B). All of them showed that Endopredict ${ }^{\circledR}$ was an independent prognostic factor. In all of them, the tumor size, nodal status, and tumor grade were included in the multivariate model.

\section{Predictive Value}

A neoadjuvant trial found that the high-risk group is associated with a higher $\mathrm{pCR}$ rate of $17 \%$ as opposed to $7 \%$ in the low-risk group, ${ }^{78}$ but LOE is currently very low about the predictive value of EndoPredict $\AA$.

\section{Long-Term Data}

Long-term data ${ }^{77,79}$ seemed to indicate that EP retained a prognostic value after 5 years. Dubsky et $\mathrm{al}^{79}$ analyzed the 1702 patients of the validation set (with ER+ HER2tumors, treated with ET alone) $)^{73}$ to evaluate the likelihood of early and late recurrence according to EP and EPclin. The EP low-risk group had an excellent long-term prognostic with an absolute freedom of distance recurrence of 96.29\% (95\% CI 93.48-99.11) between 5 and 10 years of follow-up. In multivariate analysis adjusted for age, tumor grade, nodal status, tumor size, and Ki67, the EP score remained a significant prognostic factor of both early (between 0 and 5 years, $\mathrm{HR}=1.20,95 \%$ CI 1.10-1.31, $p<$ 


\begin{tabular}{|c|c|c|c|c|}
\hline & & 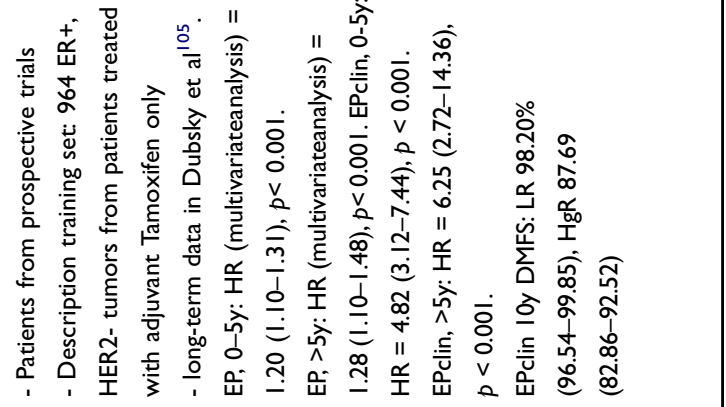 & 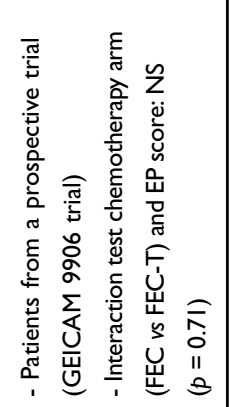 & 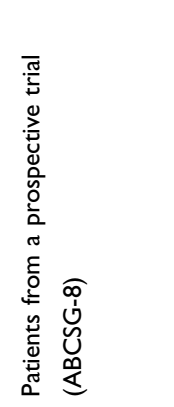 \\
\hline 童 & & 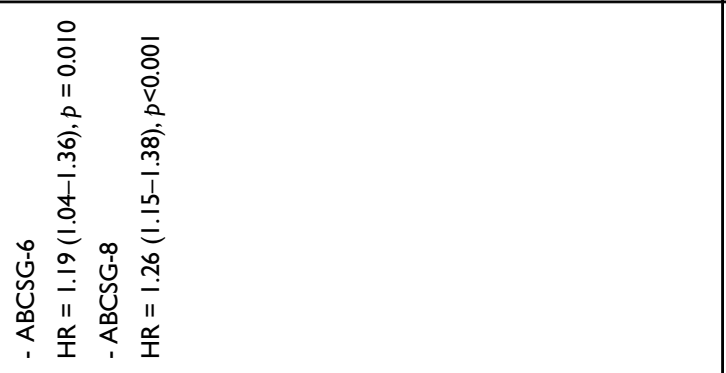 & 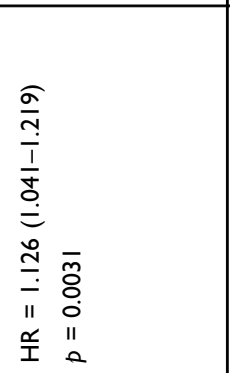 & 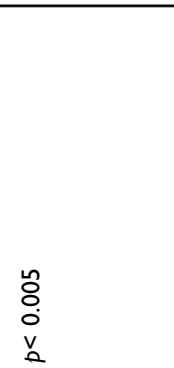 \\
\hline 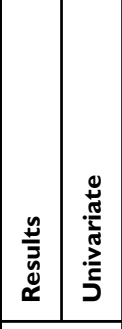 & & 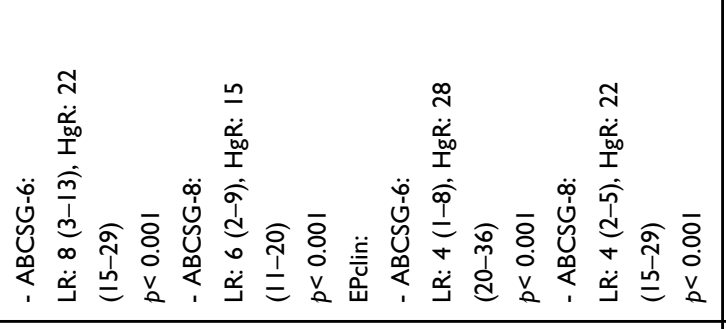 & 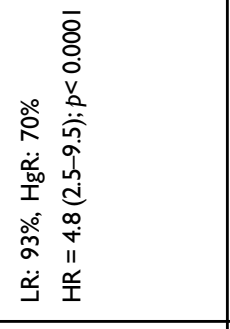 & 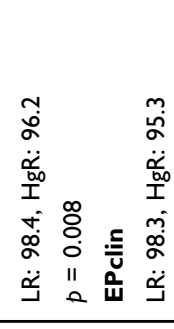 \\
\hline 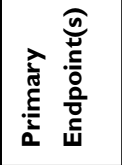 & & 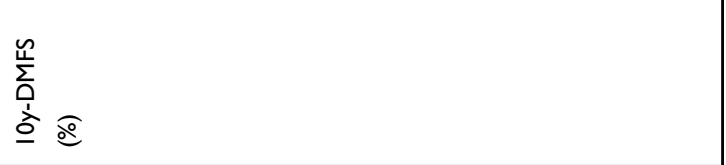 & 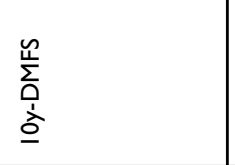 & 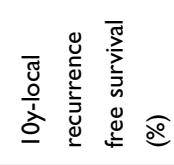 \\
\hline 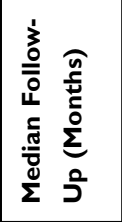 & & 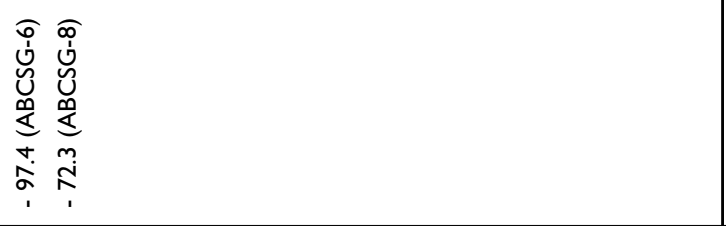 & 安 & $\overbrace{i}^{m}$ \\
\hline 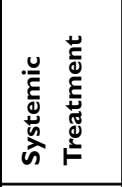 & & 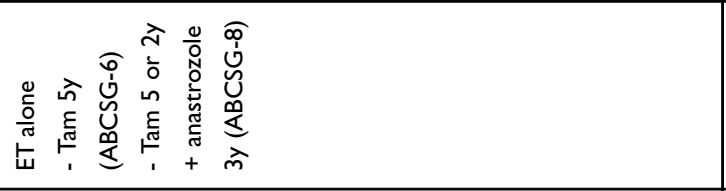 & 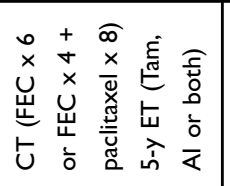 & 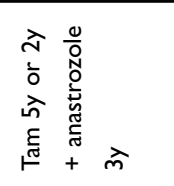 \\
\hline & & 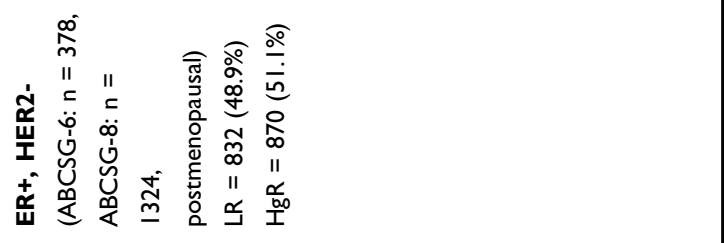 & 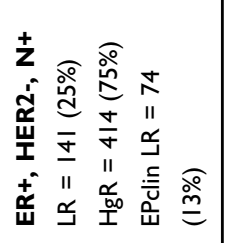 & 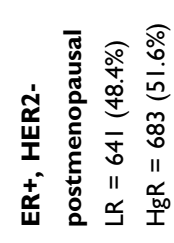 \\
\hline$z$ & & 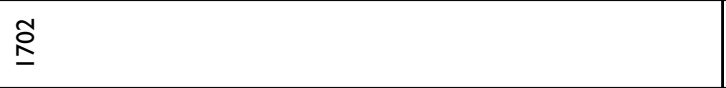 & 虽 & 志 \\
\hline & 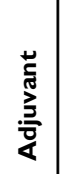 & 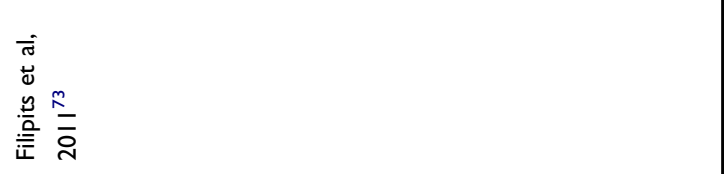 & 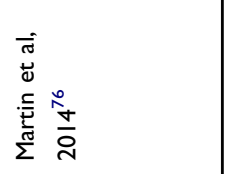 & 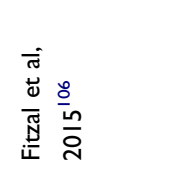 \\
\hline
\end{tabular}




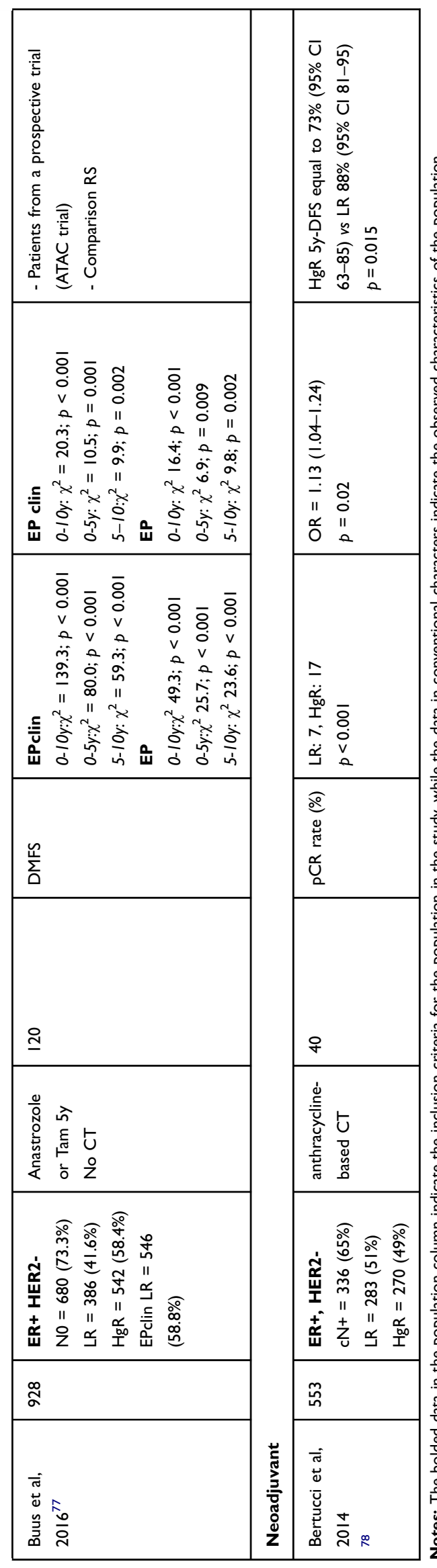

0.001 ) and late recurrence (after 5 years, $\mathrm{HR}=1.28,95 \%$ CI $1.10-1.48, p=0.001)$. The fact that EPclin takes into account clinical factors improves even more the ability of the test to detect late recurrence events (after 5 years, $\mathrm{HR}=6.25,95 \%$ CI 2.72-14.36, $p<0.001$ ) and allowed identifying a low-risk group with an excellent prognosis at 10 years, ie, an absolute freedom of distance recurrence of $98.20 \%$ (95\% CI 96.54-99.85).

This was not found in another retrospective study with a very heterogeneous population (including HER2+ tumors), in which the EP score was significant only in ER+ patients during the first 5 years. ${ }^{80}$

\section{Clinical Utility}

At the time of our search, we found no prospective data regarding EndoPredict ${ }^{\circledR}$.

\section{Recommendations and Conclusions}

According to the ASCO recommendations, EndoPredict ${ }^{\circledR}$ may be used to guide decision on adjuvant chemotherapy in case of ER or PR positive HER2-negative pN0 breast cancer, as it allows identifying a group with an excellent prognosis at 10 years in which chemotherapy could be avoided (IIB LOE). ${ }^{14}$

This test could also be useful to identify patients at risk of late recurrence who could benefit from an extended adjuvant ET. This hypothesis needs to be evaluated in a prospective study. The clinical utility of this test is not shown yet.

\section{PAM50 (Table 4) Introduction}

The PAM50 (Prediction Analysis of Microarray) signature was initially developed to classify the tumors into the intrinsic subtypes defined by the molecular classification, using microarrays. A qRT-PCR was then developed, which allowed the use of PAM50 on FFPE tumor samples. Then, 1900 genes qualified as "intrinsic" were identified, in a first step, from 122 breast cancer samples. Among them, 50 genes were selected to classify the tumors into four major intrinsic subtypes. ${ }^{81}$

Simultaneously, the prognostic and predictive values of the PAM50 signature were evaluated and a risk of relapse (ROR) score was calculated. Patients were allocated into three groups: low, intermediate, and high ROR score. A ROR-C score combining subtypes and tumor size was also developed.

Based on PAM50, the Prosigna ${ }^{\circledR}$ assay was developed for decentralized testing in local laboratories and is currently used. It simultaneously measures the expression levels of the 50 target genes by RT-PCR on the NanoStringnCounterDx Analysis System. ${ }^{82}$ An algorithm, adding information on 


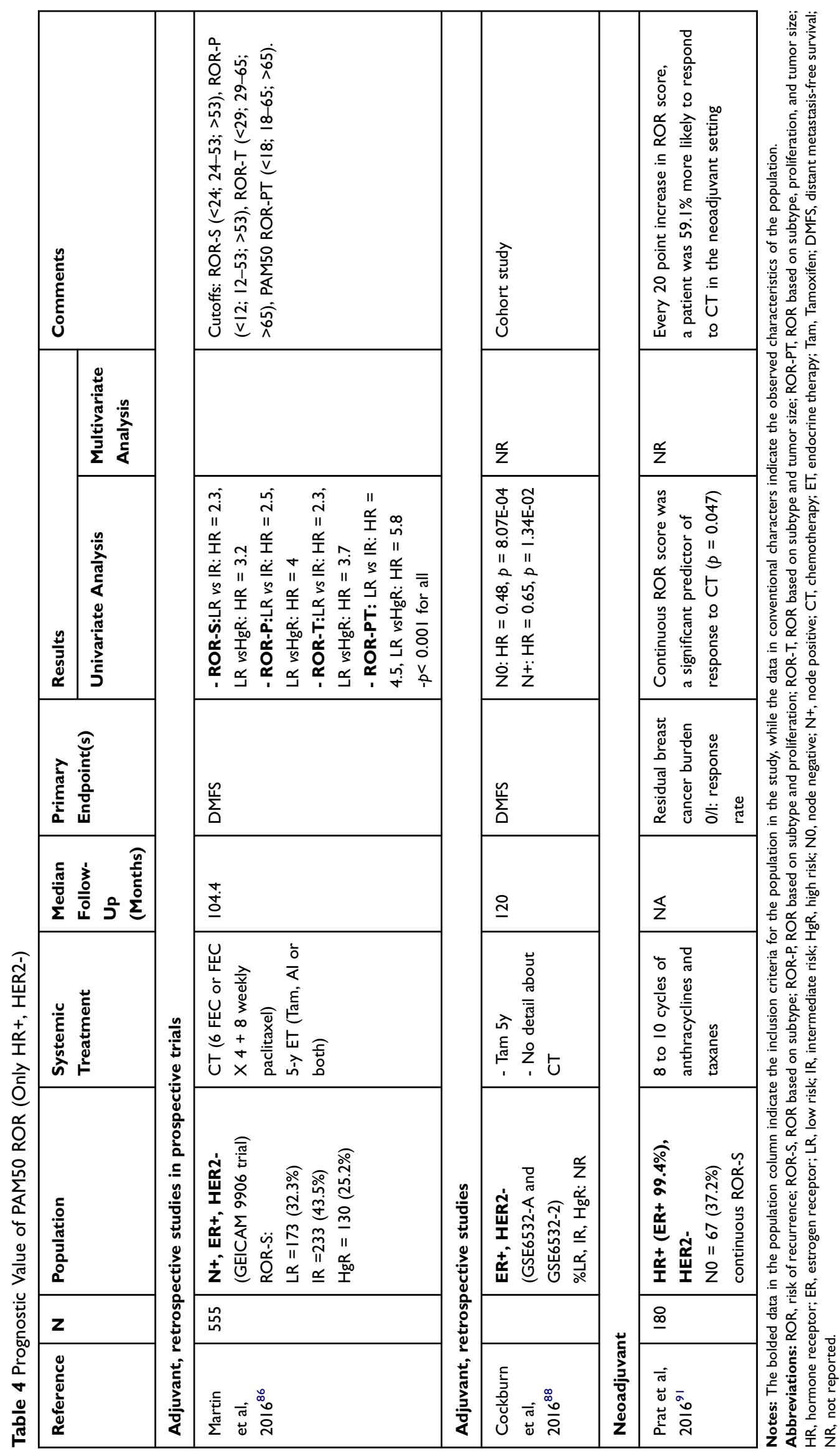


tumor size and number of involved nodes to the results of the RT-PCR, provides the four following results: the molecular subtype of the tumor, the individual likelihood of recurrence at 10 years, the ROR score in a scale from 0 to 100 , and the classification into a group of 10-year recurrence risk (low, intermediate, or high).

The test was studied in different populations of $\mathrm{pN} 0$ or $\mathrm{pN}+, \mathrm{ER}+$ or ER-, HER2+ or HER2- early breast cancer.

\section{Clinical Validity \\ Prognostic Value}

Retrospective studies using data from patients in prospective trials ${ }^{83-86}$ and retrospective studies ${ }^{44,80,87,88}$ found a prognostic value of the ROR score in ER+ HER2- pN0 or $\mathrm{pN}+$ populations as described in Table $\mathrm{S} 5$ in Supplementary data. The ROR score was often analyzed as a continuous risk score. In a population of 1017 ER+ patients from the ATAC trial, there was a continuous relationship between the ROR score and the 10-year risk of distant recurrence, with a significant difference in multivariate analysis $\left(\mathrm{LR} \Delta \chi^{2}=34.5, p<0.001\right) .{ }^{84}$ The difference in terms of 10-year DFS was also significant in a population of $1478 \mathrm{ER}+$ patients from ABCSG-8 trial, with an increase in the risk of relapse of $37.5 \%$ for an increase of 10 points in ROR score (in multivariate analysis, HR=1.03, IC 95\% $(1.02-1.04), p<0.001) .{ }^{85}$ In most studies on PAM50, the population is very diverse, encompassing more than the target population. Only 3 studies considered only a population with $\mathrm{HR}+$, HER2- tumors (Table 4), and none of them evaluated PAM50 in a multivariate model.

Analysis of long-term data of ATAC and ABCSG-8 trials $^{54,89,90}$ in $\mathrm{HR}+$ patients found that the ROR score remained significant on DMFS after 5 years (in multivariate analysis, $\mathrm{HR}=1.80 \mathrm{IC} 95 \%(1.57-2.06), p<0.001) .{ }^{90}$ Other studies found a decrease in significance after 5 years. ${ }^{80,87}$

\section{Predictive Value}

In neoadjuvant trials, the high-risk group seemed associated with higher rates of $\mathrm{pCR}$ or response to chemotherapy $^{68,91}$ and a lower rate of response to ET. ${ }^{92}$ The association between the rate of $\mathrm{pCR}$ and the ROR score in multivariate analysis was not significant ${ }^{68}$ or not reported. ${ }^{91,92}$ Only one of them assessed the signature in a population of strictly $\mathrm{HR}+$, HER2tumors.

\section{Clinical Utility}

The OPTIMA trial (Optimal Personalised Treatment of early breast cancer usIng Multi-parameter Analysis; ISRCTN42400492) is currently ongoing to evaluate the clinical utility of Prosigna ${ }^{\circledR}$. Recruitment began in January 2017. It includes patients over 40 years of age, with ER+, HER2-, early breast cancer with 1-9 involved axillary lymph nodes or tumors of a size greater than $30 \mathrm{~mm}$. They are randomized between chemotherapy and endocrine therapy or treatment according to Prosigna ${ }^{\circledR}$ (chemotherapy and endocrine therapy or endocrine therapy alone). Their population of interest corresponds well to the population in which the question of adjuvant chemotherapy arises, according to clinical and pathological criteria. The combination of clinical and genomic data seems interesting to optimize therapeutic management.

\section{Recommendations and Conclusions}

Currently, there is a lot of evidence that PAM50 is adequate to determine the risk of relapse at 10 years, but there are no data regarding its clinical utility. Considering that PAM50 classifies the patients in 3 risk groups, there is still the downside of the intermediate-risk group, which represented between $25 \%$ and $60 \%$ of the population of the published studies. The standard of care is not yet defined in this situation.

According to the ASCO recommendations, the PAM50 ROR score may be used in ER/PR positive, HER2 negative, pN0 breast cancer to guide decision on adjuvant chemotherapy with a IB LOE. In case of low ROR score, chemotherapy was not recommended, whereas it was recommended for patients with a high ROR score. No treatment recommendation was made in case of intermediate score. The signature was not recommended in case of $\mathrm{pN}+$ disease. $^{14}$

The results of the OPTIMA study are awaited in order to conclude on the clinical utility of Prosigna ${ }^{\circledR}$. Recruitment is planned until 2021 with a target of 4500 patients included.

\section{Invasive Lobular Carcinoma}

Many of the previously described tests have been developed on invasive ductal carcinoma (IDC) samples. Indeed, among the selected studies, only few of them describe the histological type of each breast cancer considered.

In two studies involving 128 ILC, UPA and PAI-1 levels were lower in ILC $(n=94)$ than in IDC $(p<$ 
$0.001)^{93}$ and lobular histology was correlated with the low-risk group in univariate analysis $(n=34) .^{94}$

Two studies on the Oncotype $\mathrm{DX}^{\circledR}$ test described ILC subgroups. ${ }^{51,95}$ In the study of Barcenas et al, ILC represented 172 cases among 1424 breast cancers (12\%), mostly in the intermediate-risk group (73\%), and only $19 \%$ and $8 \%$ in the low-risk and high-risk groups, respectively. ${ }^{51}$ In a neoadjuvant study, among 72 breast cancers, only $4(5.6 \%)$ were ILC and none of them achieved a clinical complete response. ${ }^{95}$ Their risk groups were not specified in this study.

Six studies of MammaPrint ${ }^{\circledR}$ focused on ILC breast cancers. $^{64,67,69,71,96,97}$ In the four studies in which they were assessed, $40-100 \%$ of the ILC were categorized as low risk. ${ }^{64,67,71,96}$

Only one study on the EndoPredict ${ }^{\circledR}$ test described an ILC subgroup with only 10 cases $(1.8 \%$ of the studied population). No details about the Endopredict ${ }^{\circledR}$ results were provided. ${ }^{78}$

Only one study on the PAM50 signature described a group of $61(7.8 \%)$ ILC among 786 breast cancers and no information were provided about the ROR score for this histological subtype. ${ }^{87}$

To conclude, the lack of data about ILC in the literature makes it difficult to evaluate the impact of these predictive and prognostic tests in this specific histological subtype. In our opinion, further researches are warranted to establish the clinical validity and utility of these different signatures for ILC. It would be particularly interesting to obtain data on the histological type from studies with the EndoPredict ${ }^{\circledR}$ score, which may be able to identify late relapse events.

\section{Comparisons of the Signatures}

Some studies compared the prognostic efficiency of the different signatures in a single population ${ }^{41,77,80,84,86,91,98}$ and other studies compared the correlation between different biomarkers without evaluating the impact on the survival. ${ }^{99-102}$

Overall, all these studies showed that each test has the ability to distinguish prognostic groups. The correlation is moderate to strong depending on the study (Table 5). Despite these correlations, at the individual level, a patient can be assigned to a different risk group depending on the test used. Moreover, there is no comparison of the ability for these tests to guide the treatment decision in improved clinical outcome, that is to say, regarding their clinical utility.

\section{Conclusion}

The five biomarkers evaluated showed their clinical validity to identify patients with HR+ HER2- and $\mathrm{pN} 0$ or $\mathrm{pN}+$ breast cancers at low or high risk of recurrence. They are currently available in common practice. However, only few data from prospective randomized trials are available to conclude about their clinical utility (none for PAM50 and EndoPredict ${ }^{\circledR}$ ).

Only a few studies with a high level of evidence have been conducted to evaluate the different genomic

Table 5 Correlation Between Signatures

\begin{tabular}{|c|c|c|c|c|}
\hline & upA/PAI-I & Oncotype $\mathbf{D X}{ }^{\circledR}$ & Mammaprint $^{\circledR}$ & PAM50 ROR \\
\hline Oncotype DX ${ }^{\circledR}$ & NR & & & \\
\hline Mammaprint $^{\circledR}$ & $N R$ & $\begin{array}{l}\text { - Cramer's } \bigvee \text { statistic }=0.6^{41,98} \\
-r=0.68^{44} \\
\text { - Pearson correlation }=0.65^{80} \\
\text { - Kappa }=0.40(0.30 \text { to } 0.49)^{101}\end{array}$ & & \\
\hline PAM50 ROR & NR & $\begin{array}{l}-r=0.39^{84} \\
-r=0.76^{44} \\
-r=0.08^{99} \\
- \text { Pearson correlation }=0.78^{80} \\
\text { - kappa }=0.44(0.33 \text { to } 0.54)^{101}\end{array}$ & $\begin{array}{l}-r=0.64^{44} \\
\text { - Pearson correlation }=0.68^{80} \\
\text { - kappa }=0.53(0.43 \text { to } 0.63)^{101}\end{array}$ & \\
\hline Endopredict $^{\circledR}$ & $\begin{array}{l}\text {-EPclinvs uPA: } \\
\text { kappa }=0.313(P<0.00 I) \\
- \text { EPclinvs PAI-I } \\
\text { kappa }=0.176(P=0.066)^{102}\end{array}$ & $\begin{array}{l}- \text { kappa }=0.41(\text { EPclin })^{77} \\
- \text { Pearson correlation }=0.82^{80} \\
-r=0.65^{100}\end{array}$ & - Pearson correlation $=0.68^{80}$ & $\begin{array}{l}-r=0.72^{86} \\
\text { - Pearson correlation }=0.81^{80}\end{array}$ \\
\hline
\end{tabular}

Abbreviation: NR not reported. 
signatures. The prognostic value of uPA/PAI-1 has been demonstrated in trials that included a large population of different types of breast cancer, including ER+ and ERtumors. The HER2 status was often not available. Despite a LOE 1 for its clinical validity, no trial was designed to conclude about its clinical utility, even less in our target population. The results of the TAILORx trial showed that the patients with a low RS had an excellent 5-year DFS with adjuvant ET alone and that chemotherapy did not improve 9-year DFS in the group of patients with an intermediate RS. However, the added value of the Oncotype $\mathrm{DX}^{\circledR}$ test in this population is yet unknown because all anatomopathological data currently used in multidisciplinary tumor boards were not provided in the literature. The design of the TAILORx trial also does not allow us to conclude on the clinical utility of Oncotype DX ${ }^{\circledR}$ since it has not been compared to conventional management using clinicopathological criteria. The first results of the MINDACT trial showed the interest of Mammaprint ${ }^{\mathbb{R}}$ in patients with a high clinical risk (according to the usual clinicopathological data) and low genomic risk tumors, saving them from the potential side-effects of chemotherapy with an increase of only $1.5 \%$ of the 5 -year risk of distant recurrence in comparison with those which received chemotherapy. This trial was specifically designed to answer the question of the clinical utility of Mammaprint ${ }^{\mathbb{B}}$ but had limitations in statistical analysis and missing data to conclude. The OPTIMA trial is recruiting and seems well designed to evaluate the clinical utility of Prosigna ${ }^{\circledR}$. To date, no prospective trial has been conducted to evaluate the clinical utility of EndoPredict ${ }^{\mathbb{R}}$.

A key issue is to identify the population of interest, in which the decision of adjuvant chemotherapy is difficult using only classical clinicopathological data. With experimented anatomopathologists and using data such as age, tumor size, nodal status, tumor grade, Ki67, mitotic index, histology, perivascular invasion, and intensity of staining of HR, this population is probably smaller than the population studied in the different trials. The results of the MINDACT trial showed that Mammaprint ${ }^{\circledR}$ has no added value for the patients at low clinical risk. It seems therefore essential to precisely identify the groups of patients for whom using a test to decide the therapeutic strategy is relevant. Notably, there are only few data about some specific histological tumor subtypes such as ILC, for which specific studies are needed. It is thus all the more necessary considering that two of these tests classify the patients in three groups (Oncotype DX ${ }^{\circledR}$, PAM50 ROR), with an intermediate group in which the treatment strategy is not defined, not helpful in clinical practice. In addition, the cost of these tests is an important factor to limit their indication only to situations where they could influence the therapeutic strategy.

Furthermore, the correlation between the tests is poor at the individual level. Each signature will not classify a given patient at the same level of recurrence risk. The secondgeneration signatures (PAM50, EndoPredict ${ }^{\mathbb{B}}$ ), which combine the genomic analysis with the clinical data (tumor size and nodal status), make it possible to refine the estimation of the recurrence risk and seem promising despite the current lack of prospective randomized trials. In addition, the PAM50 signature gives a supplementary result with the molecular classification of the tumor.

Finally, these tests could perhaps give us information to determine the duration of ET. Their prognostic value seems better during the first 5 years. However, some of them (particularly Endopredict ${ }^{\circledR}$ ) maintain a prognostic value after 5 years and could help to estimate the risk of late recurrence. This could be interesting to identify patients who could benefit from an extended ET of 10 years. That issue remains to be demonstrated.

Another axis of development could be a more refined classification of HR+/HER2- tumors. Indeed, the identification of subtypes of breast cancer is in continuous development. A recent study found a heterogeneity of luminal A breast cancers that could respond differently to ET or immunotherapy. ${ }^{103}$ Identification of new tumor subtypes and refinement of their taxonomy could provide additional information in order to adapt treatment to patients in the idea of personalized medicine. However, a prospective validation of their clinical utility would be mandatory.

Many anatomopathological elements (including tumor size and grade, nodal status, Ki67, the mitotic index, histological type, peri-vascular invasion and the intensity of HR staining) are considered by the multidisciplinary tumor boards in order to help make the decision on adjuvant chemotherapy. Today, the available studies did not address the question of adjuvant chemotherapy decision in the population for which the tumor boards are discussing the indications despite the classical variables. In addition, their design, variable description, or statistical analysis limitations preclude us for definitively conclude as to their clinical utility. Prospective trials focusing only on the target population HR+ HER2-, designed to compare the prognostic and/or predictive 
accuracy of these tests with the use of clinicopathological criteria, are needed.

\section{Acknowledgements}

The authors thank Hélène de Forges, Ph.D., for editorial assistance.

\section{Funding}

This research did not receive any specific grant from funding agencies in the public, commercial, or not-forprofit sectors.

\section{Disclosure}

The authors declared no conflict of interest.

\section{References}

1. Early Breast Cancer Trialists' Collaborative Group (EBCTCG), Peto R, Davies C, et al. Comparisons between different polychemotherapy regimens for early breast cancer: meta-analyses of long-term outcome among 100,000 women in 123 randomised trials. Lancet Lond Engl. 2012;379(9814):432-444. doi:10.1016/ S0140-6736(11)61625-5.

2. Munoz D, Near AM, van Ravesteyn NT, et al. Effects of screening and systemic adjuvant therapy on ER-specific US breast cancer mortality. J Natl Cancer Inst. 2014;106(11). doi:10.1093/jnci/dju289

3. Early Breast Cancer Trialists' Collaborative Group (EBCTCG). Effects of chemotherapy and hormonal therapy for early breast cancer on recurrence and 15-year survival: an overview of the randomised trials. Lancet Lond Engl. 2005;365(9472):1687-1717. doi:10.1016/S0140-6736(05)66544-0.

4. Gnant M, Steger GG. Fighting overtreatment in adjuvant breast cancer therapy. Lancet Lond Engl. 2009;374(9707):2029-2030. doi:10.1016/S0140-6736(09)62097-3

5. Mook S, Schmidt MK, Rutgers EJ, et al. Calibration and discriminatory accuracy of prognosis calculation for breast cancer with the online Adjuvant! program: a hospital-based retrospective cohort study. Lancet Oncol. 2009;10(11):1070-1076. doi:10.1016/S1470-2045(09) 70254-2

6. Olivotto IA, Bajdik CD, Ravdin PM, et al. Population-based validation of the prognostic model ADJUVANT! for early breast cancer. J Clin Oncol off J Am Soc Clin Oncol. 2005;23 (12):2716-2725. doi:10.1200/JCO.2005.06.178

7. Wishart GC, Bajdik CD, Dicks E, et al. PREDICT Plus: development and validation of a prognostic model for early breast cancer that includes HER2. Br J Cancer. 2012;107(5):800-807. doi:10.1038/ bjc. 2012.338

8. Perou CM, Sørlie T, Eisen MB, et al. Molecular portraits of human breast tumours. Nature. 2000;406(6797):747-752. doi:10.1038/ 35021093

9. Sørlie T, Perou CM, Tibshirani R, et al. Gene expression patterns of breast carcinomas distinguish tumor subclasses with clinical implications. Proc Natl Acad Sci U S A. 2001;98(19):10869-10874. doi:10.1073/pnas. 191367098

10. Pusztai L, Mazouni C, Anderson K, Wu Y, Symmans WF. Molecular classification of breast cancer: limitations and potential. Oncologist. 2006;11(8):868-877. doi:10.1634/theoncologist.11-8-868
11. Curtis BA, Tanifuji G, Burki F, et al. Algal genomes reveal evolutionary mosaicism and the fate of nucleomorphs. Nature. 2012;492 (7427):59-65. doi:10.1038/nature11681

12. Goldhirsch A, Wood WC, Coates AS, et al. Strategies for subtypesdealing with the diversity of breast cancer: highlights of the St. Gallen International Expert Consensus on the Primary Therapy of Early Breast Cancer 2011. Ann Oncol off J Eur Soc Med Oncol. 2011;22(8):1736-1747. doi:10.1093/annonc/mdr304

13. Guiu S, Michiels S, André F, et al. Molecular subclasses of breast cancer: how do we define them? The IMPAKT 2012 working group statement. Ann Oncol off J Eur Soc Med Oncol. 2012;23 (12):2997-3006. doi:10.1093/annonc/mds586

14. Harris LN, Ismaila N, McShane LM, et al. Use of biomarkers to guide decisions on adjuvant systemic therapy for women with early-stage invasive breast cancer: american society of clinical oncology clinical practice guideline. J Clin Oncol off J Am Soc Clin Oncol. 2016;34 (10):1134-1150. doi:10.1200/JCO.2015.65.2289

15. Teutsch SM, Bradley LA, Palomaki GE, et al. The Evaluation of Genomic Applications in Practice and Prevention (EGAPP) initiative: methods of the EGAPP working group. Genet Med off J Am Coll Med Genet. 2009;11:3-14. doi:10.1097/GIM.0b013e318184137c

16. Luporsi E, Bellocq J-P, Barrière J, et al. uPA/PAI-1, Oncotype $\mathrm{DX}^{\mathrm{TM}}$, MammaPrint ${ }^{\circledR}$. Valeurs pronostique et prédictive pour une utilité clinique dans la prise en charge du cancer du sein. [uPA/PAI1, Oncotype $\mathrm{DX}^{\mathrm{TM}}$, MammaPrint($(\mathbb{R})$. Prognosis and predictive values for clinical utility in breast cancer management]. Bull Cancer (Paris). 2015;102(9):719-729. French. doi:10.1016/j. bulcan.2015.05.003

17. Hayes DF, Bast RC, Desch CE, et al. Tumor marker utility grading system: a framework to evaluate clinical utility of tumor markers. J Natl Cancer Inst. 1996;88:1456-1466. doi:10.1093/jnci/88.20.1456

18. Simon RM, Paik S, Hayes DF. Use of archived specimens in evaluation of prognostic and predictive biomarkers. J Natl Cancer Inst. 2009;101:1446-1452. doi:10.1093/jnci/djp335

19. Lamy P-J, Romieu G, Jacot W. uPA/PAI-1: un outil d'individualisation de la prise en charge des cancers du sein. Biologie, implications cliniques et méthodes de dosage. [UPA/PAI-1: a tool for breast cancer treatment individualization. Biology, clinical implications and quantification assays]. Bull Cancer (Paris). 2010;97 (3):341-348. French. doi:10.1684/bdc.2010.1047

20. Dass K, Ahmad A, Azmi AS, Sarkar SH, Sarkar FH. Evolving role of uPA/uPAR system in human cancers. Cancer Treat Rev. 2008;34 (2):122-136. doi:10.1016/j.ctrv.2007.10.005

21. Duffy MJ, O'Grady P, Devaney D, O'Siorain L, Fennelly JJ, Lijnen HJ. Urokinase-plasminogen activator, a marker for aggressive breast carcinomas. Preliminary report. Cancer. 1988;62 (3):531-533. doi:10.1002/1097-0142(19880801)62:3<531::AIDCNCR2820620315>3.0.CO;2-B

22. Jänicke $F$, Schmitt $M$, Graeff $H$. Clinical relevance of the urokinase-type and tissue-type plasminogen activators and of their type 1 inhibitor in breast cancer. Semin Thromb Hemost. 1991;17 (3):303-312. doi:10.1055/s-2007-1002624

23. Benraad TJ, Geurts-Moespot J, Grøndahl-Hansen $J$, et al. Immunoassays (ELISA) of urokinase-type plasminogen activator (uPA): report of an EORTC/BIOMED-1 workshop. Eur J Cancer Oxf Engl. 1996;32A(8):1371-1381.

24. Jänicke F, Prechtl A, Thomssen C, et al. Randomized adjuvant chemotherapy trial in high-risk, lymph node-negative breast cancer patients identified by urokinase-type plasminogen activator and plasminogen activator inhibitor type 1. J Natl Cancer Inst. 2001;93(12):913-920. doi:10.1093/jnci/93.12.913

25. Look MP, van Putten WLJ, Duffy MJ, et al. Pooled analysis of prognostic impact of urokinase-type plasminogen activator and its inhibitor PAI-1 in 8377 breast cancer patients. J Natl Cancer Inst. 2002;94(2):116-128. doi:10.1093/jnci/94.2.116 
26. Harbeck N, Schmitt M, Meisner C, et al. Ten-year analysis of the prospective multicentre Chemo-N0 trial validates American Society of Clinical Oncology (ASCO)-recommended biomarkers uPA and PAI-1 for therapy decision making in node-negative breast cancer patients. Eur J Cancer. 2013;49(8):1825-1835. doi:10.1016/j.ejca.2013.01.007

27. Viala M, Alexandre M, Thezenas S, et al. Prognostic impact of the inclusion of uPA/PAI-1 for adjuvant treatment decision-making in ER+/Her2- pN0 early breast cancers. Breast Cancer Res Treat. 2017;165:611-621. doi:10.1007/s10549-017-4373-7

28. Harbeck N, Kates RE, Look MP, et al. Enhanced benefit from adjuvant chemotherapy in breast cancer patients classified high-risk according to urokinase-type plasminogen activator (uPA) and plasminogen activator inhibitor type $1(\mathrm{n}=3424)$. Cancer Res. 2002;62(16):4617-4622.

29. Borstnar S, Sadikov A, Mozina B, Cufer T. High levels of uPA and PAI-1 predict a good response to anthracyclines. Breast Cancer Res Treat. 2010;121(3):615-624. doi:10.1007/s10549-009-0691-8

30. Kantelhardt EJ, Vetter M, Schmidt M, et al. Prospective evaluation of prognostic factors uPA/PAI-1 in node-negative breast cancer: phase III NNBC3-Europe trial (AGO, GBG, EORTC-PBG) comparing $6 \times \mathrm{FEC}$ versus $3 \times \mathrm{FEC} / 3 \times$ Docetaxel. BMC Cancer. 2011;11:140. doi:10.1186/1471-2407-11-140

31. Paik S, Shak S, Tang G, et al. A multigene assay to predict recurrence of tamoxifen-treated, node-negative breast cancer. $N$ Engl J Med. 2004;351(27):2817-2826. doi:10.1056/NEJMoa041588

32. Cronin M, Sangli C, Liu M-L, et al. Analytical validation of the Oncotype DX genomic diagnostic test for recurrence prognosis and therapeutic response prediction in node-negative, estrogen receptor-positive breast cancer. Clin Chem. 2007;53(6):1084-1091. doi:10.1373/clinchem.2006.076497

33. Drury S, Salter J, Baehner FL, Shak S, Dowsett M. Feasibility of using tissue microarray cores of paraffin-embedded breast cancer tissue for measurement of gene expression: a proof-of-concept study. J Clin Pathol. 2010;63(6):513-517. doi:10.1136/jcp. 2010.075754

34. Paik S, Tang G, Shak S, et al. Gene expression and benefit of chemotherapy in women with node-negative, estrogen receptor-positive breast cancer. J Clin Oncol off J Am Soc Clin Oncol. 2006;24(23):3726-3734. doi:10.1200/JCO.2005.04.7985

35. Goldstein LJ, Gray R, Badve S, et al. Prognostic utility of the 21-gene assay in hormone receptor-positive operable breast cancer compared with classical clinicopathologic features. J Clin Oncol off J Am Soc Clin Oncol. 2008;26(25):4063-4071. doi:10.1200/ JCO.2007.14.4501

36. Dowsett M, Cuzick J, Wale C, et al. Prediction of risk of distant recurrence using the 21-gene recurrence score in node-negative and node-positive postmenopausal patients with breast cancer treated with anastrozole or tamoxifen: a TransATAC study. J Clin Oncol off J Am Soc Clin Oncol. 2010;28(11):1829-1834. doi:10.1200/ JCO.2009.24.4798

37. van 't Veer LJ, Dai H, van de Vijver MJ, et al. Gene expression profiling predicts clinical outcome of breast cancer. Nature. 2002;415(6871):530-536. doi:10.1038/415530a

38. Sapino A, Roepman P, Linn SC, et al. MammaPrint molecular diagnostics on formalin-fixed, paraffin-embedded tissue. $J \mathrm{Mol}$ Diagn JMD. 2014;16(2):190-197. doi:10.1016/j.jmoldx.2013. 10.008

39. Buyse M, Loi S, Van't Veer L, et al. Validation and clinical utility of a 70-gene prognostic signature for women with node-negative breast cancer. J Natl Cancer Inst. 2006;98(17):1183-1192. doi:10.1093/jnci/djj329

40. Habel LA, Shak S, Jacobs MK, et al. A population-based study of tumor gene expression and risk of breast cancer death among lymph node-negative patients. Breast Cancer Res BCR. 2006;8 (3):R25. doi:10.1186/bcr1412
41. Espinosa E, Sánchez-Navarro I, Gámez-Pozo A, et al. Comparison of prognostic gene profiles using qRT-PCR in paraffin samples: a retrospective study in patients with early breast cancer. PLoS One. 2009;4(6):e5911. doi:10.1371/journal.pone.00 05911

42. Toi M, Iwata H, Yamanaka $\mathrm{T}$, et al. Clinical significance of the 21-gene signature (Oncotype DX) in hormone receptor-positive early stage primary breast cancer in the Japanese population. Cancer. 2010;116(13):3112-3118. doi:10.1002/cncr.25206

43. Sun B, Zhang F, Wu S-K, et al. Gene expression profiling for breast cancer prognosis in Chinese populations. Breast J. 2011;17 (2):172-179. doi:10.1111/j.1524-4741.2010.01049.x

44. Prat A, Parker JS, Fan C, et al. Concordance among gene expression-based predictors for ER-positive breast cancer treated with adjuvant tamoxifen. Ann Oncol off J Eur Soc Med Oncol. 2012;23(11):2866-2873. doi:10.1093/annonc/mds080

45. Naoi Y, Kishi K, Tsunashima R, et al. Comparison of efficacy of 95-gene and 21-gene classifier (Oncotype DX) for prediction of recurrence in ER-positive and node-negative breast cancer patients. Breast Cancer Res Treat. 2013;140(2):299-306. doi:10.1007/ s10549-013-2640-9

46. Mamounas EP, Tang G, Fisher B, et al. Association between the 21-gene recurrence score assay and risk of locoregional recurrence in node-negative, estrogen receptor-positive breast cancer: results from NSABP B-14 and NSABP B-20. J Clin Oncol off $J$ Am Soc Clin Oncol. 2010;28(10):1677-1683. doi:10.1200/ JCO.2009.23.7610

47. Wolmark N, Mamounas EP, Baehner FL, et al. Prognostic Impact of the combination of recurrence score and quantitative estrogen receptor expression (ESR1) on predicting late distant recurrence risk in estrogen receptor-positive breast cancer after 5 years of tamoxifen: results from NRG oncology/national surgical adjuvant breast and bowel project B-28 and B-14. J Clin Oncol off J Am Soc Clin Oncol. 2016;34(20):2350-2358. doi:10.1200/JCO.2015.62. 6630

48. Yorozuya K, Takeuchi T, Yoshida M, et al. Evaluation of oncotype DX recurrence score as a prognostic factor in Japanese women with estrogen receptor-positive, node-negative primary stage I or IIA breast cancer. J Cancer Res Clin Oncol. 2010;136(6):939-944. doi:10.1007/s00432-009-0736-8

49. Albain KS, Barlow WE, Shak S, et al. Prognostic and predictive value of the 21-gene recurrence score assay in postmenopausal women with node-positive, oestrogen-receptor-positive breast cancer on chemotherapy: a retrospective analysis of a randomised trial. Lancet Oncol. 2010;11(1):55-65. doi:10.1016/S14702045(09)70314-6

50. Mamounas EP, Liu Q, Paik S, et al. 21-gene recurrence score and locoregional recurrence in node-positive/ER-positive breast cancer treated with chemo-endocrine therapy. $J$ Natl Cancer Inst. 2017;109(4). doi:10.1093/jnci/djw259

51. Barcenas $\mathrm{CH}$, Raghavendra A, Sinha AK, et al. Outcomes in patients with early-stage breast cancer who underwent a 21-gene expression assay. Cancer. 2017;123:2422-2431. doi:10.1002/cncr.30618

52. Le Du F, Gonzalez-Angulo AM, Park M, Liu DD, Hortobagyi GN, Ueno NT. Effect of 21-gene RT-PCR assay on adjuvant therapy and outcomes in patients with stage I breast cancer. Clin Breast Cancer. 2015;15(6):458-466. doi:10.1016/j. clbc.2015.06.006

53. Wen HY, Krystel-Whittemore M, Patil S, et al. Breast carcinoma with an oncotype Dx recurrence score $<18$ : rate of distant metastases in a large series with clinical follow-up. Cancer. 2017;123 (1):131-137. doi:10.1002/cncr.30271

54. Sestak I, Dowsett M, Zabaglo L, et al. Factors predicting late recurrence for estrogen receptor-positive breast cancer. J Natl Cancer Inst. 2013;105(19):1504-1511. doi:10.1093/jnci/djt244 
55. Sgroi DC, Sestak I, Cuzick J, et al. Prediction of late distant recurrence in patients with oestrogen-receptor-positive breast cancer: a prospective comparison of the breast-cancer index (BCI) assay, 21-gene recurrence score, and IHC4 in the TransATAC study population. Lancet Oncol. 2013;14(11):1067-1076. doi:10.1016/S1470-2045(13)70387-5

56. Sparano JA, Gray RJ, Makower DF, et al. Prospective validation of a 21-gene expression assay in breast cancer. $N$ Engl $J$ Med. 2015;373(21):2005-2014. doi:10.1056/NEJMoa1510764

57. Gluz O, Nitz UA, Christgen M, et al. West German Study Group Phase III planb trial: first prospective outcome data for the 21-gene recurrence score assay and concordance of prognostic markers by central and local pathology assessment. J Clin Oncol off J Am Soc Clin Oncol. 2016;34 (20):2341-2349. doi:10.1200/JCO.2015.63.5383

58. Sparano JA, Paik S. Development of the 21-gene assay and its application in clinical practice and clinical trials. J Clin Oncol off J Am Soc Clin Oncol. 2008;26(5):721-728. doi:10.1200/JCO.2007.15.1068

59. Sparano JA, Gray RJ, Makower DF, et al. Adjuvant chemotherapy guided by a 21 -gene expression assay in breast cancer. $N$ Engl J Med. 2018;379(2):111-121. doi:10.1056/NEJMoa1804710

60. Sparano JA, Gray RJ, Ravdin PM, et al. Clinical and genomic risk to guide the use of adjuvant therapy for breast cancer. $N$ Engl $J$ Med. 2019;380(25):2395-2405. doi:10.1056/NEJMoa1904819

61. Glas AM, Floore A, Delahaye LJMJ, et al. Converting a breast cancer microarray signature into a high-throughput diagnostic test. BMC Genomics. 2006;7:278. doi:10.1186/1471-2164-7-278

62. van de Vijver MJ, He YD, Van't Veer LJ, et al. A gene-expression signature as a predictor of survival in breast cancer. $N$ Engl J Med. 2002;347(25):1999-2009. doi:10.1056/NEJMoa021967

63. Bueno-de-Mesquita JM, Linn SC, Keijzer R, et al. Validation of 70 -gene prognosis signature in node-negative breast cancer. Breast Cancer Res Treat. 2009;117(3):483-495. doi:10.1007/s10549-0080191-2

64. Mook S, Schmidt MK, Weigelt B, et al. The 70-gene prognosis signature predicts early metastasis in breast cancer patients between 55 and 70 years of age. Ann Oncol off J Eur Soc Med Oncol. 2010;21(4):717-722. doi:10.1093/annonc/mdp388

65. Kok M, Koornstra RH, Mook S, et al. Additional value of the 70-gene signature and levels of ER and PR for the prediction of outcome in tamoxifen-treated ER-positive breast cancer. Breast Edinb Scotl. 2012;21(6):769-778. doi:10.1016/j.breast.2012.04.010

66. Drukker CA, van Tinteren H, Schmidt MK, et al. Long-term impact of the 70-gene signature on breast cancer outcome. Breast Cancer Res Treat. 2014;143(3):587-592. doi:10.1007/s10549-013-2831-4

67. Straver ME, Glas AM, Hannemann J, et al. The 70-gene signature as a response predictor for neoadjuvant chemotherapy in breast cancer. Breast Cancer Res Treat. 2010;119(3):551-558. doi:10.1007/s10549-009-0333-1

68. Esserman LJ, Berry DA, Cheang MCU, et al. Chemotherapy response and recurrence-free survival in neoadjuvant breast cancer depends on biomarker profiles: results from the I-SPY 1 TRIAL (CALGB 150007/150012; ACRIN 6657). Breast Cancer Res Treat. 2012;132(3):1049-1062. doi:10.1007/s10549-011-1895-2

69. Whitworth P, Beitsch P, Mislowsky A, et al. Chemosensitivity and endocrine sensitivity in clinical luminal breast cancer patients in the prospective Neoadjuvant Breast Registry Symphony Trial (NBRST) predicted by molecular subtyping. Ann Surg Oncol. 2017;24(3):669-675. doi:10.1245/s10434-016-5600-x

70. Cardoso F, Van't Veer LJ, Bogaerts J, et al. 70-gene signature as an aid to treatment decisions in early-stage breast cancer. $N$ Engl $J$ Med. 2016;375(8):717-729. doi:10.1056/NEJMoa1602253

71. Mook S, Schmidt MK, Viale G, et al. The 70-gene prognosis-signature predicts disease outcome in breast cancer patients with 1-3 positive lymph nodes in an independent validation study. Breast Cancer Res Treat. 2009;116(2):295-302. doi:10.1007/ s10549-008-0130-2
72. Krop I, Ismaila N, Andre F, et al. Use of biomarkers to guide decisions on adjuvant systemic therapy for women with early-stage invasive breast cancer: american society of clinical oncology clinical practice guideline focused update. $J$ Clin Oncol off J Am Soc Clin Oncol. 2017;35(24):2838-2847. doi:10.1200/ JCO.2017.74.0472

73. Filipits M, Rudas M, Jakesz R, et al. A new molecular predictor of distant recurrence in ER-positive, HER2-negative breast cancer adds independent information to conventional clinical risk factors. Clin Cancer Res off J Am Assoc Cancer Res. 2011;17 (18):6012-6020. doi:10.1158/1078-0432.CCR-11-0926

74. Denkert C, Kronenwett R, Schlake W, et al. Decentral gene expression analysis for ER+/Her2- breast cancer: results of a proficiency testing program for the EndoPredict assay. Virchows Arch Int J Pathol. 2012;460(3):251-259. doi:10.1007/s00428-0121204-4

75. Kronenwett R, Bohmann K, Prinzler J, et al. Decentral gene expression analysis: analytical validation of the Endopredict genomic multianalyte breast cancer prognosis test. BMC Cancer. 2012;12:456. doi:10.1186/1471-2407-12-456

76. Martin M, Brase JC, Calvo L, et al. Clinical validation of the EndoPredict test in node-positive, chemotherapy-treated ER +/HER2- breast cancer patients: results from the GEICAM 9906 trial. Breast Cancer Res BCR. 2014;16(2):R38. doi:10.1186/ bcr3642

77. Buus R, Sestak I, Kronenwett R, et al. Comparison of endopredict and epclin with oncotype DX recurrence score for prediction of risk of distant recurrence after endocrine therapy. J Natl Cancer Inst. 2016;108(11). doi:10.1093/jnci/djw149

78. Bertucci F, Finetti P, Viens P, Birnbaum D. EndoPredict predicts for the response to neoadjuvant chemotherapy in ER-positive, HER2-negative breast cancer. Cancer Lett. 2014;355(1):70-75. doi:10.1016/j.canlet.2014.09.014

79. Dubsky P, Brase JC, Jakesz R, et al. The EndoPredict score provides prognostic information on late distant metastases in ER +/HER2- breast cancer patients. Br J Cancer. 2013;109 (12):2959-2964. doi:10.1038/bjc.2013.671

80. Zhao X, Rødland EA, Sørlie T, et al. Systematic assessment of prognostic gene signatures for breast cancer shows distinct influence of time and ER status. BMC Cancer. 2014;14:211. doi:10.1186/1471-2407-14-211

81. Parker JS, Mullins M, Cheang MCU, et al. Supervised risk predictor of breast cancer based on intrinsic subtypes. J Clin Oncol off $J$ Am Soc Clin Oncol. 2009;27(8):1160-1167. doi:10.1200/ JCO.2008.18.1370

82. Wallden B, Storhoff J, Nielsen T, et al. Development and verification of the PAM50-based Prosigna breast cancer gene signature assay. BMC Med Genomics. 2015;8. doi:10.1186/s12920-0150129-6

83. Chia SK, Bramwell VH, Tu D, et al. A 50-gene intrinsic subtype classifier for prognosis and prediction of benefit from adjuvant tamoxifen. Clin Cancer Res off J Am Assoc Cancer Res. 2012;18 (16):4465-4472. doi:10.1158/1078-0432.CCR-12-0286

84. Dowsett M, Sestak I, Lopez-Knowles E, et al. Comparison of PAM50 risk of recurrence score with oncotype DX and IHC4 for predicting risk of distant recurrence after endocrine therapy. J Clin Oncol off J Am Soc Clin Oncol. 2013;31(22):2783-2790. doi:10.1200/JCO.2012.46.1558

85. Gnant M, Filipits M, Greil R, et al. Predicting distant recurrence in receptor-positive breast cancer patients with limited clinicopathological risk: using the PAM50 risk of recurrence score in 1478 postmenopausal patients of the ABCSG-8 trial treated with adjuvant endocrine therapy alone. Ann Oncol off $J$ Eur Soc Med Oncol. 2014;25(2):339-345. doi:10.1093/ annonc/mdt494 
86. Martin M, Brase JC, Ruiz A, et al. Prognostic ability of EndoPredict compared to research-based versions of the PAM50 risk of recurrence (ROR) scores in node-positive, estrogen receptor-positive, and HER2-negative breast cancer. A GEICAM/ 9906 sub-study. Breast Cancer Res Treat. 2016;156(1):81-89. doi:10.1007/s10549-016-3725-z

87. Nielsen TO, Parker JS, Leung S, et al. A comparison of PAM50 intrinsic subtyping with immunohistochemistry and clinical prognostic factors in tamoxifen-treated estrogen receptor-positive breast cancer. Clin Cancer Res off J Am Assoc Cancer Res. 2010;16 (21):5222-5232. doi:10.1158/1078-0432.CCR-10-1282

88. Cockburn JG, Hallett RM, Gillgrass AE, et al. The effects of lymph node status on predicting outcome in ER+/HER2- tamoxifen treated breast cancer patients using gene signatures. BMC Cancer. 2016;16:555. doi:10.1186/s12885-016-2501-0

89. Filipits M, Nielsen TO, Rudas M, et al. The PAM50 risk-ofrecurrence score predicts risk for late distant recurrence after endocrine therapy in postmenopausal women with endocrine-responsive early breast cancer. Clin Cancer Res. 2014;20(5):1298-1305. doi:10.1158/1078-0432.CCR-13-1845

90. Sestak I, Cuzick J, Dowsett M, et al. Prediction of late distant recurrence after 5 years of endocrine treatment: a combined analysis of patients from the Austrian breast and colorectal cancer study group 8 and arimidex, tamoxifen alone or in combination randomized trials using the PAM50 risk of recurrence score. J Clin Oncol off J Am Soc Clin Oncol. 2015;33(8):916-922. doi:10.1200/ JCO.2014.55.6894

91. Prat A, Galván P, Jimenez B, et al. Prediction of response to neoadjuvant chemotherapy using core needle biopsy samples with the prosigna assay. Clin Cancer Res off J Am Assoc Cancer Res. 2016;22(3):560-566. doi:10.1158/1078-0432.CCR-15-0630

92. Dunbier AK, Anderson H, Ghazoui Z, et al. Association between breast cancer subtypes and response to neoadjuvant anastrozole. Steroids. 2011;76(8):736-740. doi:10.1016/j.steroids.2011.02.025

93. Descotes F, Riche B, Saez S, et al. Plasminogen activator inhibitor type 1 is the most significant of the usual tissue prognostic factors in node-negative breast ductal adenocarcinoma independent of urokinase-type plasminogen activator. Clin Breast Cancer. 2008;8 (2):168-177. doi:10.3816/CBC.2008.n.018

94. De Cremoux P, Grandin L, Diéras V, et al. Urokinase-type plasminogen activator and plasminogen-activator-inhibitor type 1 predict metastases in good prognosis breast cancer patients. Anticancer Res. 2009;29(5):1475-1482.

95. Chang JC, Makris A, Gutierrez MC, et al. Gene expression patterns in formalin-fixed, paraffin-embedded core biopsies predict docetaxel chemosensitivity in breast cancer patients. Breast Cancer Res Treat. 2008;108(2):233-240. doi:10.1007/s10549-007-9590-Z
96. Saghatchian M, Mook S, Pruneri G, et al. Additional prognostic value of the 70-gene signature (MammaPrint $\left({ }^{\circledR}\right)$ ) among breast cancer patients with 4-9 positive lymph nodes. Breast Edinb Scotl. 2013;22(5):682-690. doi:10.1016/j.breast.2012.12.002

97. Thomassen M, Tan Q, Eiriksdottir F, Bak M, Cold S, Kruse TA. Prediction of metastasis from low-malignant breast cancer by gene expression profiling. Int $J$ Cancer. 2007;120(5):1070-1075. doi:10.1002/ijc.22449

98. Fan C, Oh DS, Wessels L, et al. Concordance among gene-expressionbased predictors for breast cancer. N Engl J Med. 2006;355(6):560-569. doi:10.1056/NEJMoa052933

99. Alvarado MD, Prasad C, Rothney M, et al. A prospective comparison of the 21-gene recurrence score and the PAM50-based prosigna in estrogen receptor-positive early-stage breast cancer. $A d v$ Ther. 2015;32(12):1237-1247. doi:10.1007/s12325-015-0269-2

100. Varga Z, Sinn P, Fritzsche F, et al. Comparison of endopredict and oncotype DX test results in hormone receptor positive invasive breast cancer. PLoS One. 2013;8(3):e58483. doi:10.1371/journal. pone.0058483

101. Bartlett JMS, Bayani J, Marshall A, et al. Comparing breast cancer multiparameter tests in the OPTIMA prelim trial: no test is more equal than the others. J Natl Cancer Inst. 2016;108(9). doi:10.1093/ jnci/djw050

102. Ettl J, Klein E, Hapfelmeier A, et al. Decision impact and feasibility of different ASCO-recommended biomarkers in early breast cancer: prospective comparison of molecular marker EndoPredict and protein marker uPA/PAI-1. PLoS One. 2017;12(9):e0183917. doi:10.1371/journal.pone.0183917

103. Poudel P, Nyamundanda G, Patil Y, Cheang MCU, Sadanandam A. Heterocellular gene signatures reveal luminal-A breast cancer heterogeneity and differential therapeutic responses. NPJ Breast Cancer. 2019;5:21. doi:10.1038/s41523-019-0116-8

104. Soran A, Bhargava R, Johnson R, et al. The impact of Oncotype DX® recurrence score of paraffin-embedded core biopsy tissues in predicting response to neoadjuvant chemotherapy in women with breast cancer. Breast Dis. 2016;36(2-3):65-71. doi:10.3233/BD-150199

105. Dubsky P, Filipits M, Jakesz R, et al. EndoPredict improves the prognostic classification derived from common clinical guidelines in ER-positive, HER2-negative early breast cancer. Ann Oncol off J Eur Soc Med Oncol. 2013;24(3):640-647. doi:10.1093/annonc/ mds334

106. Fitzal F, Filipits M, Rudas M, et al. The genomic expression test EndoPredict is a prognostic tool for identifying risk of local recurrence in postmenopausal endocrine receptor-positive, her2neu-negative breast cancer patients randomised within the prospective ABCSG 8 trial. $\mathrm{Br}$ J Cancer. 2015;112(8):1405-1410. doi:10.1038/bjc.2015.98

\section{Publish your work in this journal}

Cancer Management and Research is an international, peer-reviewed open access journal focusing on cancer research and the optimal use of preventative and integrated treatment interventions to achieve improved outcomes, enhanced survival and quality of life for the cancer patient.
The manuscript management system is completely online and includes a very quick and fair peer-review system, which is all easy to use. Visit http://www.dovepress.com/testimonials.php to read real quotes from published authors. 